\title{
WestVirginiaUniversity
}

THE RESEARCH REPOSITORY @ WVU

Graduate Theses, Dissertations, and Problem Reports

2009

\section{Removal of phosphorus/selenium from aqueous solutions by adsorption processes}

Shilpa Bhojappa

West Virginia University

Follow this and additional works at: https://researchrepository.wvu.edu/etd

\section{Recommended Citation}

Bhojappa, Shilpa, "Removal of phosphorus/selenium from aqueous solutions by adsorption processes" (2009). Graduate Theses, Dissertations, and Problem Reports. 4441.

https://researchrepository.wvu.edu/etd/4441

This Thesis is protected by copyright and/or related rights. It has been brought to you by the The Research Repository @WVU with permission from the rights-holder(s). You are free to use this Thesis in any way that is permitted by the copyright and related rights legislation that applies to your use. For other uses you must obtain permission from the rights-holder(s) directly, unless additional rights are indicated by a Creative Commons license in the record and/ or on the work itself. This Thesis has been accepted for inclusion in WVU Graduate Theses, Dissertations, and Problem Reports collection by an authorized administrator of The Research Repository @ WVU. For more information, please contact researchrepository@mail.wvu.edu. 


\title{
Removal of Phosphorus/Selenium from Aqueous Solutions by Adsorption Processes
}

\author{
Shilpa Bhojappa \\ Thesis submitted to the \\ College of Engineering and Mineral Resources \\ at West Virginia University \\ in partial fulfillment of the requirements \\ for the degree of \\ Master of Science \\ In \\ Civil Engineering
}

Xinchao Wei, Ph.D., Chair

Lian-Shin Lin, Ph.D.

Karen M. Buzby, Ph.D.

Department of Civil and Environmental Engineering

Morgantown, West Virginia

2009

Keywords: Adsorption, Phosphorus removal, Tertiary treatment, Selenium Removal, Nano-magnetite, Adsorption Isotherm

Copyright 2009 Shilpa Bhojappa 


\section{ABSTRACT \\ Removal of Phosphorus/Selenium from Aqueous Solutions by Adsorption Processes}

Shilpa Bhojappa

The present study includes two parts : (1) Acid mine drainage (AMD) sludge, a waste product from coal mine water treatment, was used as an adsorbent to develop a cost-effective treatment approach to phosphorus removal from municipal secondary effluents. (2) Synthesized nano-magnetite was used as an adsorbent to develop an innovative technology for selenium removal from aqueous solutions. Each case involved a series of batch adsorption experiments conducted to evaluate adsorption kinetics, isotherms, and adsorptive thermodynamics. The effects of $\mathrm{pH}$, temperature, concentration, contact time, and competing anions on the concerned pollutant removal were examined as well.

Adsorption of phosphorus onto AMD sludge particles followed the Freundlich isotherm model with an adsorption capacity ranging from $10 \mathrm{mg} / \mathrm{g}$ to $32 \mathrm{mg} / \mathrm{g}$ when the final effluent concentration increased from $0.2 \mathrm{mg}-\mathrm{P} / \mathrm{L}$ to $13.6 \mathrm{mg}-\mathrm{P} / \mathrm{L}$. Increase in temperature and neutral/acidic $\mathrm{pH}$ favored $\mathrm{P}$ adsorption. Three types of water (synthetic wastewater, river water, and municipal secondary effluent) used in a continuous stirred tank reactor (CSTR) setting showed that P adsorption by AMD sludge was relatively independent of the presence of other ionic species. In treating municipal secondary effluent, phosphorus removal efficiency in excess of $98 \%$ was obtained. Results of this study indicated that it was very promising to utilize AMD sludge for phosphorus removal from secondary effluents and may be relevant to future efforts focused on the control of eutrophication in surface waters.

Selenite adsorption onto nano-magnetite was observed within $30 \mathrm{~min}$ and low $\mathrm{pH}$ (i.e., 3.0-5.0) favored the mechanism. Thermodynamic calculations indicated the spontaneity of the process and its endothermic nature. At an initial selenite concentration of $100 \mu \mathrm{g}-\mathrm{Se} / \mathrm{L}$, more than $95 \%$ removal was achieved; resulting in an effluent concentration less than $5 \mu \mathrm{g}-\mathrm{Se} / \mathrm{L}$ with an adsorption capacity of $\sim 1 \mathrm{mg} / \mathrm{g}$. Adsorption isotherm study indicated that the adsorption of selenite onto nano-magnetite followed the Freundlich model. Adsorption kinetics was well characterized by a pseudo-second-order model. It was observed that the presence of sulfate did not significantly affect the adsorption mechanism. In conclusion, it was found that nano-magnetite was a promising low-cost adsorbent to treat aqueous solutions containing low levels (50 to $500 \mu \mathrm{g} / \mathrm{L})$ of selenium. 


\section{DEDICATION}

To my dearest daughter Navya

for

her love 


\section{ACKNOWLEDGEMENT}

My sincere thanks go to my advisor Dr. Xinchao Wei, for his incredible support, encouragement, valuable time and generosity. His guidance and insight were instrumental in the completion of my research as well as in writing my thesis. My time here at WVU has been a learning experience like no other and I have gained knowledge and skills through my advisor. In addition, I would also like to thank Dr. Lance Lin for his precious time to have served on my committee. And my gratitude goes to Dr. Karen Buzby for being a part of my committee and for her valuable inputs throughout my working days.

I acknowledge the Center for Advanced Separation Technologies (CAST) for funding this study. I would like to thank Mr. Kenneth Stewart, Analytical Laboratory Director of the National Research Center for Coal and Energy (NRCCE) and his staff for their time, help and generosity in allowing me complete my analysis at their laboratory.

My greatest thanks go to my family for their love and support, especially my husband, Harish, for his patience, understanding and encouragement. I greatly appreciate the help from my friends and fellow students: Maggie Wei, Isabel Cordona, Paola Correa, Meilin Liu, Ning Zhang, Yushun Chen and Lina Cui. The help, assistance and time that Research Assistant Will Ravenscroft imparted are sincerely acknowledged.

I thank the faculty and staff in Civil and Environmental Engineering for making this opportunity a wonderful experience. 


\section{TABLE OF CONTENTS}

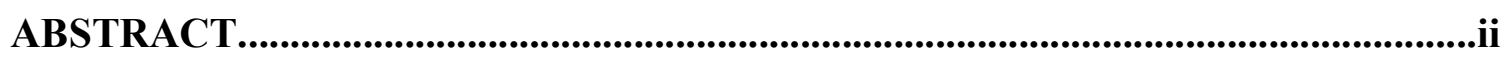

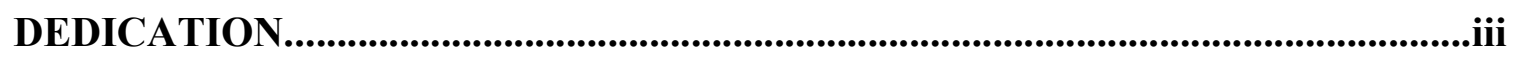

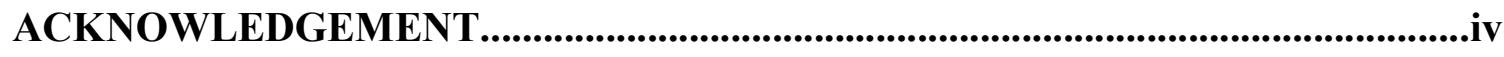

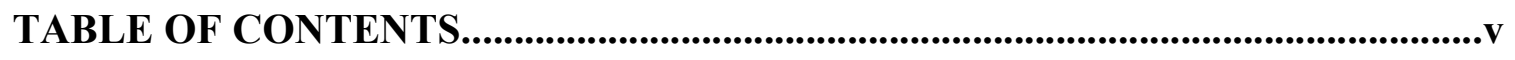

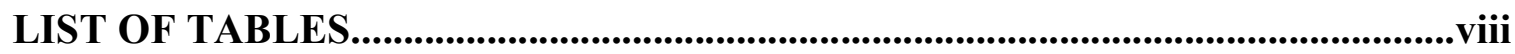

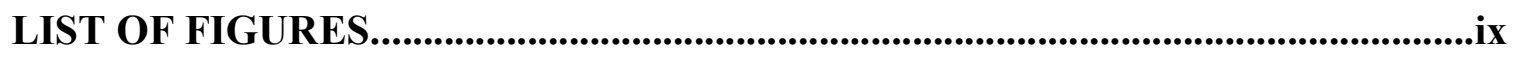

CHAPTER 1: PHOSPHORUS REMOVAL BY ACID MINE DRAINAGE SLUDGE FROM SECONDARY EFFLUENTS OF MUNICIPAL WASTEWATER TREATMENT PLANTS........................................................1

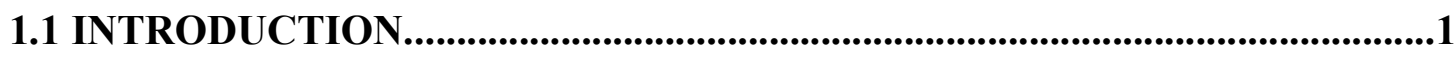

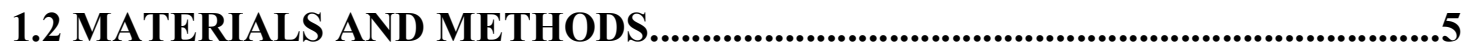

1.2.1 Adsorbent

1.2.2 Adsorbate...........................................................................................................6

1.2.3 Batch Adsorption Studies.......................................................................................6

1.2.4 Continuous Adsorption Studies.....................................................................7

1.2.5 Phosphorus Analyses.......................................................................10

1.2.6 Metal Leaching Tests...........................................................................10

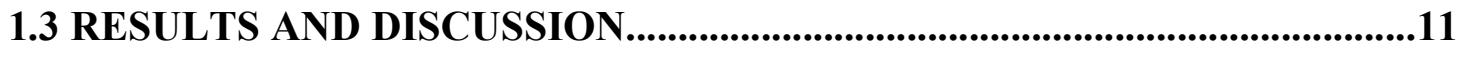

1.3.1 Effect of Sludge Dose and Contact Time......................................................11 
1.3.2 Effect of pH, Temperature and Adsorption Thermodynamics..................13

1.3.3 Adsorption Isotherms..........................................................................16

1.3.4 Resolubilization of AMD sludge-bound metals...............................................17

1.3.5 Continuous CSTR adsorption studies..........................................................18

1.3.6 Implication for nutrient removal from municipal wastewater

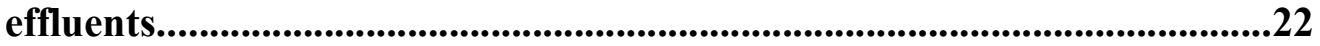

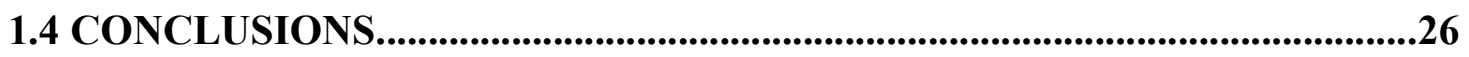

REFERENCES...................................................................27

CHAPTER 2: REMOVAL OF SELENIUM FROM AQUEOUS SOLUTIONS BY

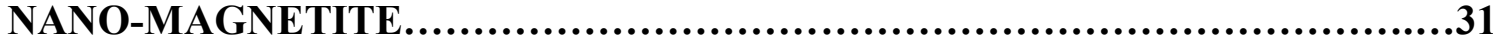

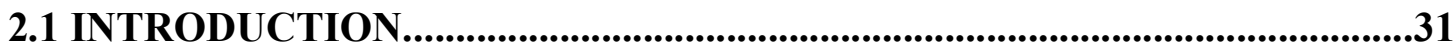

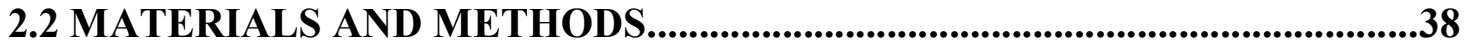

2.2.1 Materials................................................................................................38

2.2.2 Adsorbent Preparation and Characterization..........................................38

2.2.3 Batch Adsorption Studies.......................................................................................40

2.2.4 Effect of Interfering anions...................................................................41

2.3 RESULTS AND DISCUSSION..........................................................................42

2.3.1 Comparison of Nano-magnetite with Natural magnetite and

Nano-iron for selenite adsorption......................................................................42

2.3.2 Comparison of Nano-magnetite with Natural magnetite and

Nano-iron for selenate adsorption................................................................43

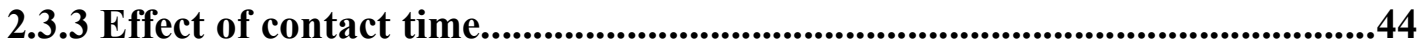


2.3.4 Effect of pH................................................................................................................46

2.3.5 Effect of temperature and Adsorption Thermodynamics...........................47

2.3.6 Adsorption isotherms....................................................................50

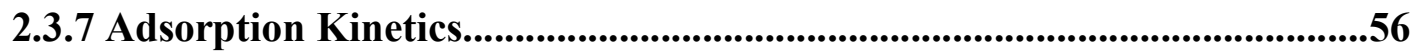

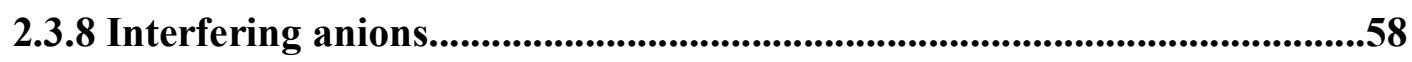

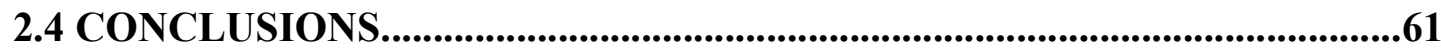

REFERENCES...............................................................62

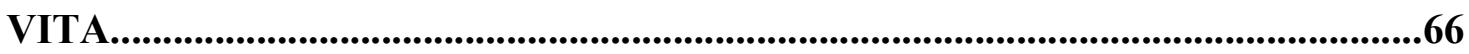




\section{LIST OF TABLES}

Table 1.1 The physicochemical characteristics of water samples from Monongahela River and a POTW secondary effluent (concentration in $\mathrm{mg} / \mathrm{L}$ except $\mathrm{pH}$ )..9

Table 1.2 Thermodynamic parameters for $P$ adsorption by AMD sludge..........16

Table 1.3 Dissolved metal concentrations $(\mathrm{mg} / \mathrm{L})$ in the effluents after $\mathrm{P}$ adsorption by AMD sludge at different $\mathrm{pH}^{1}$ (initial concentration $20 \mathrm{mg}-\mathrm{P} / \mathrm{L}$; sludge

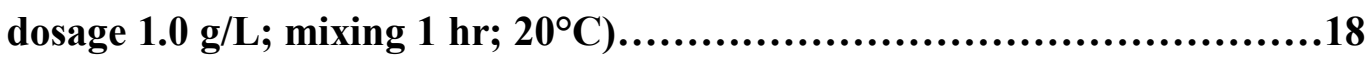

Table 2.1 Thermodynamic parameters for the adsorption of selenite on nanomagnetite at different temperatures.......................................50

Table 2.2 Freundlich, Langmuir and Elovich parameters for the adsorption of

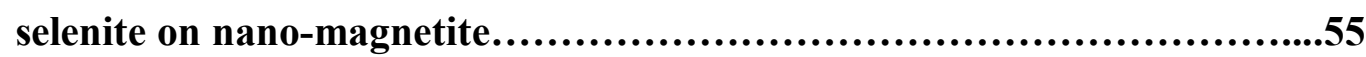

Table 2.3 Pseudo-first-order and Pseudo-second-order adsorption rate constants for the adsorption of selenite on nano-magnetite.............................58 


\section{LIST OF FIGURES}

Figure 1.1. Schematic of laboratory CSTR testing system............................8

Figure 1.2. Effect of AMD sludge dosage and contact time on effluent $P$ concentration (mean \pm 1 standard deviation). (a) sludge dose (initial concentration $20 \mathrm{mg}-\mathrm{P} / \mathrm{L} ; 20^{\circ} \mathrm{C} ; \mathrm{pH} 7.0 \pm 0.1 ;$ mixing time $1 \mathrm{~h}$; dosage 0 - 2.0 $\mathrm{g} / \mathrm{L}$ ); (b) contact time (sludge dosage $1 \mathrm{~g} / \mathrm{L} ; 20^{\circ} \mathrm{C} ; \mathrm{pH}$ 7.0 \pm 0.1 ; initial

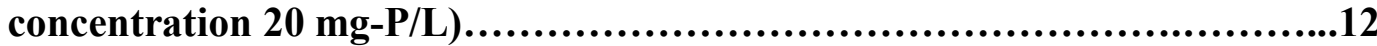

Figure 1.3. Effect of $\mathrm{pH}$ and temperature on effluent $P$ concentration (mean \pm 1 standard deviation). (a) $\mathrm{pH}$ (initial concentration $20 \mathrm{mg}-\mathrm{P} / \mathrm{L}$; sludge dosage $0.6 \mathrm{~g} / \mathrm{L}$; mixing time $1 \mathrm{hr} ; 20^{\circ} \mathrm{C}$ ); (b) temperature (initial concentration 20 mg-P/L; sludge dosage $0.6 \mathrm{~g} / \mathrm{L}$; mixing time $1 \mathrm{hr}$; $\mathrm{pH} 7 \pm 0.1) \ldots \ldots \ldots \ldots \ldots \ldots . . .14$

Figure 1.4. Freundlich isotherm of phosphorus adsorption by AMD sludge (mixing

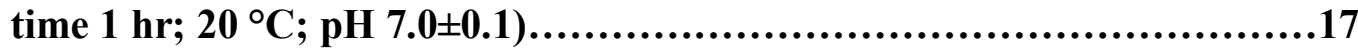

Figure 1.5. Change of effluent $P$ concentration and $\mathrm{pH}$ during CSTR tests.

(a) three types of water samples (Feed rate $2 \mathrm{~L} / \mathrm{h}$; initial concentration 20 mg-P/L; sludge dose 1g/L; hydraulic detention time $1 \mathrm{hr} ; 20^{\circ} \mathrm{C}$ ); (b) detention time (Mon River water, feed rate $1 \mathrm{~L} / \mathrm{h}$ and $2 \mathrm{~L} / \mathrm{h}$; initial concentration $20 \mathrm{mg}-\mathrm{P} / \mathrm{L}$; sludge dose $\left.1 \mathrm{~g} / \mathrm{L} ; 20^{\circ} \mathrm{C}\right)$

Figure 1.6. Change of effluent $P$ concentration and $p H$ during CSTR tests at Different AMD sludge doses for actual POTW effluent (Feed rate $2 \mathrm{~L} / \mathrm{h}$; Hydraulic detention time $1 \mathrm{hr}$; initial concentration $1.8 \mathrm{mg}-\mathrm{P} / \mathrm{L}$; sludge dose $\left.1.0 \mathrm{~g} / \mathrm{L} ; 20^{\circ} \mathrm{C}\right)$ 
Figure 1.7. Proposed processes for phosphorus removal using AMD sludge (a) typical suspended growth secondary treatment, (b) AMD sludge adsorption tertiary treatment added to a typical suspended growth system, (c) integration of AMD sludge-based adsorption into secondary treatment.....25

Figure 2.1. TEM micrograph for synthesized nano-magnetite

Figure 2.2. Effect of selenite removal by three different materials at varying dosages (mixing time $24 \mathrm{~h} ; 25^{\circ} \mathrm{C} ; \mathrm{pH} 4.0 \pm 0.1$; initial concentration $100 \mu \mathrm{g} / \mathrm{L}$ )

Figure 2.3. Effect of selenate removal by three different materials at varying dosages (mixing time $24 \mathrm{~h} ; 2^{\circ} \mathrm{C} ; \mathrm{pH} 4.0 \pm 0.1$; initial concentration $100 \mu \mathrm{g} / \mathrm{L}$ ).........44

Figure 2.4. Effect of contact time on final selenite concentration (adsorbent dose

$0.1 \mathrm{~g} / \mathrm{L} ; \mathrm{pH} 4.0 \pm 0.1 ; 25^{\circ} \mathrm{C} ; 24 \mathrm{~h}$ mixing time; initial concentrations

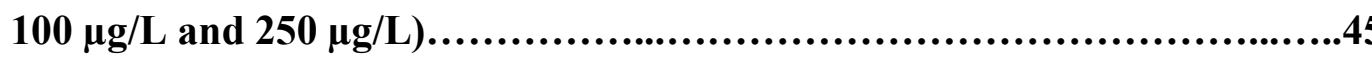

Figure 2.5. Effect of pH on final selenite concentration (adsorbent dose $0.1 \mathrm{~g} / \mathrm{L}$; pH 4.0 \pm 0.1 ; mixing time $24 \mathrm{~h} ; 20^{\circ} \mathrm{C}$; initial concentration $100 \mu \mathrm{g} / \mathrm{L}$ and

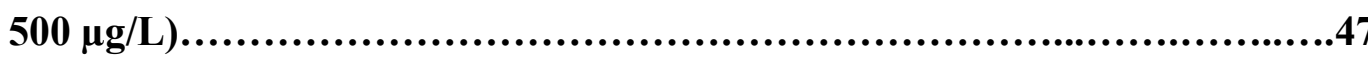

Figure 2.6. Effect of temperature on final selenite concentration( adsorbent dose $0.1 \mathrm{~g} / \mathrm{L} ; \mathrm{pH} 4.0 \pm 0.1$; mixing time $24 \mathrm{~h}$; initial concentrations 100,250

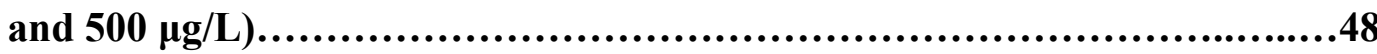

Figure 2.7. Van't Hoff plot for selenite concentration (adsorbent dose $0.1 \mathrm{~g} / \mathrm{L} ; \mathrm{pH}$ $4.0 \pm 0.1$; mixing time $24 \mathrm{~h}$; initial concentrations 100,250 and $500 \mu \mathrm{g} / \mathrm{L}) \ldots . .49$

Figure 2.8. Freundlich isotherm of selenite adsorption by nano-magnetite (adsorbent dose $0.1 \mathrm{~g} / \mathrm{L}$; mixing time $24 \mathrm{~h} ; 25^{\circ} \mathrm{C}$ ) .52

Figure 2.9. Langmuir isotherm of selenite adsorption by nano-magnetite 
(adsorbent dose $0.1 \mathrm{~g} / \mathrm{L}$; mixing time $24 \mathrm{~h} ; 25^{\circ} \mathrm{C}$ )

Figure 2.10. Elovich isotherm of selenite adsorption by nano-magnetite

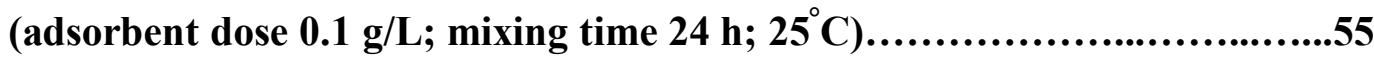

Figure 2.11. Pseudo-first-order kinetics for sorption of selenite by nano-magnetite (adsorbent dose $0.1 \mathrm{~g} / \mathrm{L}$; pH 4.0 \pm 0.1 ; mixing time $24 \mathrm{~h} ; 25^{\circ} \mathrm{C}$ ).................56

Figure 2.12. Pseudo-first-order kinetics for sorption of selenite by nano-magnetite (adsorbent dose $0.1 \mathrm{~g} / \mathrm{L}$; pH 4.0 \pm 0.1 ; mixing time $24 \mathrm{~h} ; 25^{\circ} \mathrm{C}$ ).................57

Figure 2.13 (a) - Effect of anions on selenite removal by nano-magnetite (mixing

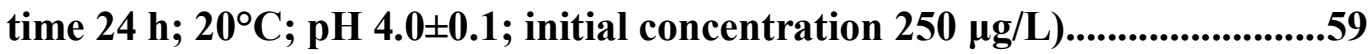

Figure 2.13 (b) - Effect of sulfate on selenite removal by nano-magnetite ( mixing time $24 \mathrm{~h} ; 20^{\circ} \mathrm{C} ; \mathrm{pH} 4.0 \pm 0.1$; initial concentration $\left.250 \mu \mathrm{g} / \mathrm{L}\right) \ldots \ldots \ldots \ldots \ldots \ldots . . . . .60$ 


\section{CHAPTER 1: PHOSPHORUS REMOVAL BY ACID MINE DRAINAGE SLUDGE FROM SECONDARY EFFLUENTS OF MUNICIPAL WASTEWATER TREATMENT PLANTS}

\subsection{Introduction}

The release of phosphorus $(\mathrm{P})$ from municipal wastewater treatment effluents into the environment is one major cause of eutrophication in receiving water bodies (Oleszkiewicz and Barnard, 2006; Edwards and Withers, 2007). In order to mitigate the growth of aquatic plants and phytoplanktonic algae, environmental agencies are required to develop phosphorus total maximum daily load (TMDL) for many watersheds (Havens and Schelske, 2001; Walker, 2003). In addition to TMDL requirements, some regulations can require the phosphorus concentration in wastewater effluents to be as low as $50 \mu \mathrm{g} / \mathrm{L}$ (Genz et al., 2004). Phosphorus exists in municipal wastewaters in different forms, including total phosphorus, soluble phosphorus, and particulate phosphorus. In general, primary and secondary treatment is effective in removing particulate phosphorus. Phosphorus in secondary effluents is mostly soluble and is present as orthophosphate (Duenas et al., 2003). Furthermore, only orthophosphate is consumed for phytoplankton growth causing eutrophication in surface water bodies (Selig et al., 2002). Consequently, tertiary treatment of secondary municipal effluents to remove orthophosphate has become increasingly necessary to meet environmental regulations worldwide.

There are a wide range of technologies available to remove phosphorus from wastewaters, such as chemical precipitation, biological treatment, adsorption processes, constructed wetlands, and a number of wastewater-and-sludge based methods (Morse et 
al., 1998; de-Bashan and Bashan, 2004), which typically require considerable capital investment and maintenance costs for infrastructure and reagents. Thus, it is desirable to develop cost-effective processes for phosphorus removal from secondary wastewater effluents. In particular, $\mathrm{P}$ adsorption using iron oxide/hydroxide and aluminum hydroxide has been recently studied and found to be successful.

Kang et al. (2003) evaluated the adsorption of orthophosphate by iron oxide particles (ferrihydrite, goethite, and hematite) and found that ferrihydrite was most effective in removing phosphorus to a very low concentration. For ferrihydrite, the Freundlich isotherm parameters were $\mathrm{K}=19.4 \mathrm{mg}-\mathrm{P} / \mathrm{g}$ and $\mathrm{n}=0.293$. Genz et al. (2004) studied the advanced phosphorus removal from membrane bioreactor effluents using activated aluminum oxide and granular ferric hydroxide (GFH). Both adsorbents were proven to be suitable for potential application in fixed bed adsorbers, while GFH showed better affinity and adsorption capacity at low phosphorus concentrations. The adsorption capacity of GFH ranged from 7.9 to $12.3 \mathrm{mg}-\mathrm{P} / \mathrm{g}$, when equilibrium $\mathrm{P}$ concentrations increased from 0.1 to $0.3 \mathrm{mg}-\mathrm{P} / \mathrm{L}$. Recovered ochre (i.e., $\mathrm{Fe}(\mathrm{OH})_{3}$ or $\mathrm{FeO} \cdot \mathrm{OH}$-rich sludge) was tested for phosphorus removal from wastewater (Heal et al., 2004). It was found that ochre had a high adsorption capacity due to its high content of iron oxide/hydroxide (maximum adsorption capacity $17.8-21.5 \mathrm{mg}-\mathrm{P} / \mathrm{g}$ ), and its potential to treat sewage effluent and agricultural runoff was assessed. Adler and Sibrell (2003) investigated the use of flocs from acid mine water neutralization to reduce the loss of soluble phosphorus from agricultural and animal wastewater, and found iron and aluminum-rich flocs were effective in controlling the release of soluble phosphorus from soil and manure. The adsorption capacities of AMD flocs ranged from 10 to $20 \mathrm{mg}-\mathrm{P} / \mathrm{g}$ at 
an equilibrium concentration of $1 \mathrm{mg}-\mathrm{P} / \mathrm{L}$. Galarneau and Gehr (1997) studied the capacity of aluminum hydroxide as an adsorbent to remove various forms of phosphorus. At a dose of 8 mol- $\mathrm{Al} / \mathrm{mol} \mathrm{P}$, the removal efficiency was $95 \%, 95 \%$ and $40 \%$ for orthophosphate, condensed phosphate and organic phosphate, respectively. Spent alum sludge, a byproduct from water treatment (mostly $\left.\mathrm{Al}(\mathrm{OH})_{3}\right)$, was also demonstrated to be effective in the removal of phosphorus from wastewater (Yang et al., 2006). The maximum adsorption capacities ranged from 0.7 to $3.5 \mathrm{mg}-\mathrm{P} / \mathrm{g}$ when $\mathrm{pH}$ varied from 9.0 to 4.3. Furthermore, quartz particles coated with iron and aluminum oxides were evaluated as a filter media to remove phosphorus from wastewater (Arias et al., 2006). The maximum adsorption capacity was $4.4 \mathrm{mg} / \mathrm{g}$ of Fe-oxide-coated particles.

Acid mine drainage (AMD), produced at both active and abandoned mines, is generally characterized by low $\mathrm{pH}$ and often high concentrations of dissolved metals (Fe, $\mathrm{Al}, \mathrm{Mn}$, and trace metals such as $\mathrm{Pb}, \mathrm{Cu}, \& \mathrm{Zn}$ ), resulting in environmental problems across the globe (Johnson and Hallberg, 2005). Typical AMD treatment processes rely on the removal of dissolved metals via precipitation. As a residual of this treatment approach, large volumes of sludge are produced. These sludges are a mixture of metal oxides/hydroxides and solids content is very low (1-5\%). When compounded by the low economic value of the waste sludge, substantial difficulties in dewatering, and the high cost of off-site hauling, the ultimate disposal of AMD sludge is problematic (Ackman, 1982; Dempsey et al., 2001; Viadero et al., 2006). In an AMD site treating a flow of 100$400 \mathrm{gal} / \mathrm{min}(400-1500 \mathrm{~L} / \mathrm{min})$ in West Virginia, USA, approximately $30,000 \mathrm{~m}^{3}$ of sludge was generated annually (Wei et al., 2005). Consequently, a major challenge in AMD treatment is the management of large volumes of loose sludge (Ackman, 1982; 
Kuyucak, 1998; Wei et al., 2005). The waste sludge is usually transported by pipeline and/or truck, and is typically disposed of through one of the following methods: deep mine disposal, retained-in-pond disposal, or disposal at coal refuse areas (Ackman, 1982; Matlock et al., 2002). However, the chemical composition of AMD sludge is mostly amorphous micron and submicron sized metal oxide/hydroxide particles. AMD sludge generally has a high specific surface area and numerous functional groups which are chemically active in an aqueous environment (Kirby et al., 1999; Cornell and Schwertmann, 2003; Wei and Viadero, 2007).

To date, very little work has been reported in the peer reviewed literature on the beneficial use of AMD sludge for phosphorus removal. However, given the wide range of studies successfully reporting $\mathrm{P}$ removal from wastewaters using $\mathrm{Fe}$ and/or $\mathrm{Al}$ hydroxide sludges, it was hypothesized that the AMD sludge containing a mixture of iron and aluminum hydroxide precipitates would be a suitable medium for the adsorption of dissolved orthophosphate from solution. The goal of this study was to develop a potentially low-cost, sustainable treatment approach to phosphorus removal from secondary wastewater effluents in which a waste product from the mining industry is used to further benefit. Batch tests were carried out to study the adsorption kinetics, isotherms, and adsorptive thermodynamics in conjunction with studies on the effects of $\mathrm{pH}$, temperature, concentration, and contact time for phosphorus removal from wastewater. Batch tests were followed by continuous flow tests using a continuous stirred tank reactor (CSTR). Based on the outcomes of these studies, the applications and implications of using AMD sludge as a tertiary process in municipal wastewater treatment were discussed. 


\subsection{Materials and methods}

\subsubsection{Adsorbent}

AMD sludge was used as an adsorbent in this study. The sludge was collected from a bond-forfeited treatment site in north central West Virginia, USA, where AMD was actively treated with hydrogen peroxide and anhydrous ammonia. The sludge was approximately one month old upon collection. The collected sludge was sieved through a fine screen (100 mesh) to remove the debris and sand entrained from the settling pond and was stored in a sealed 19-L (5-gal) container at $4^{\circ} \mathrm{C}$. The sludge suspension was very stable without the occurrence of apparent settling during storage. The total solids content of the sludge was $4.31 \%$ by weight and the $\mathrm{pH}$ was $\sim 8.1$. Based on elemental analysis, the AMD sludge was composed mainly of iron and aluminum hydroxides (Fe $26.1 \%, \mathrm{Al}$ 9.5\%, Ca 2.6\%, Mg 0.6\%, Mn 0.2\%, Zn 0.2\%, Ni 0.1\%, \& Si 4.1\%; analyzed on a dry weight basis). Before adsorption tests, the AMD sludge was mixed homogeneously and sludge samples were taken. Wet sludge ( $4.31 \%$ solids) was applied directly as adsorbent without drying because sludge drying was energy and time consuming. Further, subsequent rehydration of dried samples could have affected the surface area and the number and properties of surface active sites available for phosphorus adsorption. However, the amount of adsorbent applied during each test is reported in grams based on its dry weight (unless otherwise noted) in order to follow the convention of typical adsorption studies. 


\subsubsection{Adsorbate}

Since orthophosphate is the primary form of phosphorus responsible for eutrophication (Selig et al., 2002; Duenas et al., 2003), potassium dihydrogen phosphate $\left(\mathrm{KH}_{2} \mathrm{PO}_{4}, \mathrm{CAS \# :} \mathrm{7778-77-0),} \mathrm{acquired} \mathrm{from} \mathrm{Fisher} \mathrm{Scientific} \mathrm{(Fair} \mathrm{Lawn,} \mathrm{NJ),} \mathrm{was} \mathrm{used}\right.$ in adsorption tests as the source of orthophosphate without further purification. A stock orthophosphate solution of $20 \mathrm{mg}-\mathrm{P} / \mathrm{L}$ was prepared with laboratory grade water and used throughout the study, unless otherwise noted.

\subsubsection{Batch adsorption studies}

Batch studies were performed to examine orthophosphate adsorption onto AMD sludge by agitating $500 \mathrm{~mL}$ of a synthetic wastewater (20 mg-P/L) dosed with predetermined amounts of AMD sludge using a Phipps and Bird stirrer at $150 \mathrm{rpm}$. After adsorption equilibrium was reached (determined through laboratory tests), samples were taken and phosphorus concentrations were determined. Experiments were conducted to evaluate the effects of $\mathrm{pH}$, temperature, $\mathrm{P}$ concentration, contact time, and adsorbent dosage. The $\mathrm{pH}$ of the suspensions of orthophosphate and AMD sludge was maintained at the desired ranges by the addition of either $1 \mathrm{M} \mathrm{NaOH}$ or $0.5 \mathrm{M} \mathrm{H}_{2} \mathrm{SO}_{4}$ solution during adsorption tests. All adsorption tests were carried out in triplicate.

For the adsorption isotherm study, different amounts of AMD sludge $(0.0 \sim 1.0 \mathrm{~g})$ were added to $500 \mathrm{~mL}$ of orthophosphate solution and mixed for $1 \mathrm{hr}$ at $20^{\circ} \mathrm{C}$ and $\mathrm{pH}$ $7 \pm 0.1$. To examine adsorption kinetics, $0.5 \mathrm{~g}$ of AMD sludge was added to $500 \mathrm{~mL}$ of stock orthophosphate solution and agitated for periods of time ranging from 5 to 120 min at $\mathrm{pH} 7 \pm 0.1$, before samples were taken to determine orthophosphate concentration. 
Based on the contact time test, it was found that $1 \mathrm{~h}$ mixing was sufficient for the adsorption to reach equilibrium. To test the effect of system $\mathrm{pH}$, suspensions of $0.3 \mathrm{~g}$ AMD sludge and $500 \mathrm{~mL}$ of orthophosphate solution were adjusted in 0.5 standard unit intervals with $\mathrm{NaOH}$ or $\mathrm{H}_{2} \mathrm{SO}_{4}$ to a target $\mathrm{pH}$ ranging from 5.0 to 8.5 and mixed for $1 \mathrm{hr}$ at $20^{\circ} \mathrm{C}$.

A thermostatic water bath (Fisher Isotemp) was used to examine the effect of temperature on phosphorus adsorption by AMD sludge. First, $500 \mathrm{~mL}$ of orthophosphate solution was mixed in a beaker until the target temperature was reached. Then, $0.3 \mathrm{~g}$ adsorbent was added and mixing continued for $1 \mathrm{hr}$ at $\mathrm{pH} 7 \pm 0.1$. Test temperatures ranged from 5 to $50{ }^{\circ} \mathrm{C}$ at 5 or $10^{\circ} \mathrm{C}$ intervals. Temperatures below $20^{\circ} \mathrm{C}$ were maintained by adding ice to the water bath during testing.

\subsubsection{Continuous adsorption studies}

Continuous adsorption was carried out by using a continuous stirred tank reactor (CSTR) (Fig. 1). Three types of water used in CSTR tests were: 1) a synthetic wastewater, same as the batch adsorption tests $(20 \mathrm{mg}-\mathrm{P} / \mathrm{L}), 2)$ surface water from the Monongahela (Mon) River near Morgantown, West Virginia, USA, which was dosed to $20 \mathrm{mg}-\mathrm{P} / \mathrm{L}$, and 3) secondary effluent from an operating publicly owned treatment works (POTW). The synthetic wastewater was used to test for potential differences in phosphorus removal between CSTR systems and batch operations. However, since the synthetic wastewater was prepared with deionized water, the potential effects of competing ions, especially anions $\left(\mathrm{SO}_{4}{ }^{2-}\right.$, or $\left.\mathrm{Cl}^{-}\right)$, was unknown. Consequently, surface water from a local river was collected and tested. In order to compare the removal 
effectiveness with and without competing ions, the river water was dosed to the same phosphorus concentration used in experiments with the synthetic wastewater. Finally, the actual effluent was tested to demonstrate the effectiveness of phosphorus adsorption with AMD sludge. Typical water quality data for the Mon River and secondary effluent from a POTW used in this study are presented in Table 1.1.

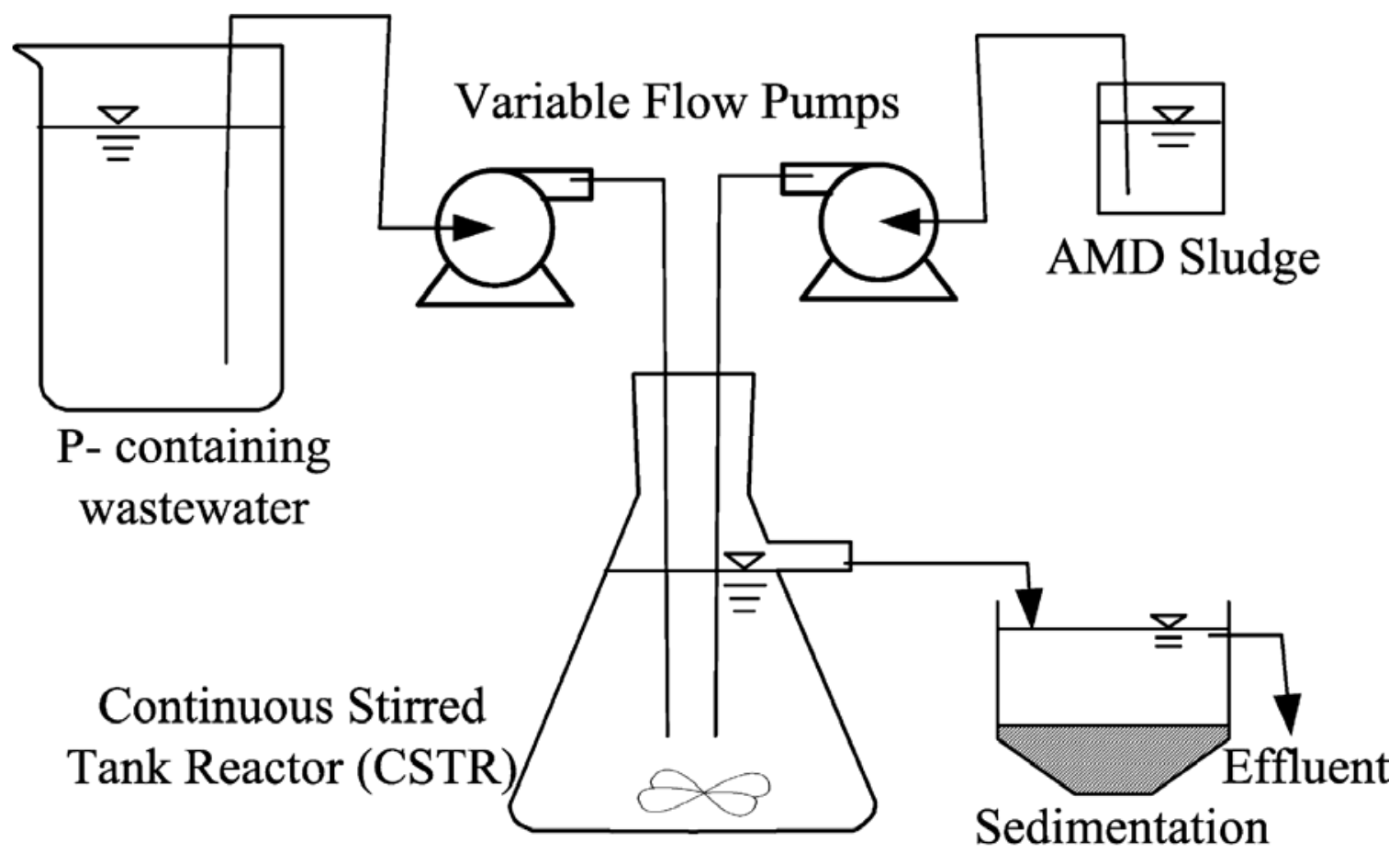

Figure 1.1 Schematic of laboratory CSTR testing system. 
Table 1.1 The physicochemical characteristics of water samples from Monongahela River and a POTW secondary effluent (concentration in $\mathrm{mg} / \mathrm{L}$ except $\mathrm{pH}$ ).

\begin{tabular}{lcc}
\hline \multicolumn{1}{c}{ Item } & $\begin{array}{c}\text { Monongahela } \\
\text { River Sample }\end{array}$ & $\begin{array}{c}\text { POTW Secondary } \\
\text { Effluent }\end{array}$ \\
\hline Acidity & 7.86 as $\mathrm{CaCO}_{3}$ & 24.27 as $\mathrm{CaCO}_{3}$ \\
Alkalinity & 67.20 as $\mathrm{CaCO}_{3}$ & 102.52 as $\mathrm{CaCO}_{3}$ \\
pH & 7.75 & 6.91 \\
Chloride & 13.5 & 76.5 \\
TSS & 3.05 & 7.54 \\
Sulfate & 697.0 & 166.6 \\
Nitrate & 0.613 & 0.450 \\
Nitrite & 0.042 & 0.241 \\
Ammonia & 0.295 & 4.45 \\
P (ortho) & 0.016 & 1.80 \\
Mn & 0.12 & 0.65 \\
$\mathrm{Fe}$ & 0.27 & 0.15 \\
$\mathrm{Ca}$ & 38.6 & 48.0 \\
$\mathrm{Mg}$ & 9.70 & 8.44 \\
$\mathrm{Al}$ & 0.37 & 0.18 \\
\hline
\end{tabular}

At the start of each test, a 2-liter CSTR was filled with the wastewater. Phosphorus-containing water was then continuously fed into the CSTR at a flow rate of 2 L/h with a variable flow pump. At the same time, well-mixed AMD sludge was fed to the reactor at a flow rate predetermined to achieve different sludge dosages $(0.35,0.5$, or 1.0 $\mathrm{g}$ (dry weight) per liter wastewater). The hydraulic residence time ( 1 or $2 \mathrm{hr}$ ) of the CSTR was adjusted by varying the feed rate of the wastewater. The system was operated continuously for a period of 3 to $5 \mathrm{hr}$ until equilibrium was reached. The resulting effluent was sampled at specific time intervals (10 to $25 \mathrm{~min}$ ). All tests were conducted in triplicate and the mean values were reported (variability of triplicate data was within $\pm 5 \%$ 
of the mean). No $\mathrm{pH}$ adjustment was made in CSTR tests, although $\mathrm{pH}$ was monitored every time water samples were taken.

\subsubsection{Phosphorus analyses}

Orthophosphate was measured according to Standard Method 4500-P E (APHA, 1998) with a method detection limit (MDL) of $0.01 \mathrm{mg}-\mathrm{P} / \mathrm{L}$. Ascorbic acid, ammonium molybdate and potassium antimonyl tartrate were used for color development and the orthophosphate concentration was determined using a Genesys 10/UV-Vis spectrophotometer based on a calibration curve between absorbance and concentration at a wave length of $880 \mathrm{~nm}$. Prior to measurement, the solids in the water samples were removed via centrifugation for $10 \mathrm{~min}$ at 4,000 $\mathrm{rpm}$ (Sorvall $\mathrm{RC}-5 \mathrm{C}$ centrifuge) and the supernatant was filtered through $0.45 \mu \mathrm{m}$ membrane (Millipore). For quality control and assurance, blank and spiked samples were treated the same way as water samples to assess potential sample contamination and determine "analytic recovery" of phosphorus. Further, $\mathrm{P}$ analysis was completed the same day as testing and the membrane filters were soaked in distilled water for $24 \mathrm{hrs}$ prior to use, according to Standard Method 4500-P B (APHA, 1998).

\subsubsection{Metal leaching tests}

Metal leaching experiments were carried out to determine if metals were leaching from the AMD sludge during adsorption. The tests were performed by agitating a $500 \mathrm{~mL}$ sample of orthophosphate solution dosed with $0.5 \mathrm{~g}$ AMD sludge for $1 \mathrm{~h}$ at a $\mathrm{pH}$ ranging from 5 to 9 , in 1 standard unit increments. After agitation, samples were taken and 
filtered through a $0.45 \mu \mathrm{m}$ membrane. The concentrations of dissolved metals (Fe, $\mathrm{Al}$, $\mathrm{Mn}, \mathrm{Zn}, \mathrm{Ni}, \& \mathrm{Cu})$ in the filtrate were determined according to Standard Method 3111 (APHA, 1998), using an atomic absorption spectrometer (Perkin Elmer 3100; MDLs are presented in Table 3). All experimental controls were performed using $500 \mathrm{~mL}$ of deionized water ( $0 \mathrm{mg} / \mathrm{L}$ orthophosphate) and $0.5 \mathrm{~g}$ AMD sludge at $\mathrm{pH} \sim 8.1$.

\subsection{Results and discussion}

\subsubsection{Effect of sludge dose and contact time}

The relationship between effluent $\mathrm{P}$ concentration and AMD sludge dose is presented in Fig. 1.2(a). The effluent $\mathrm{P}$ concentration decreased rapidly as the AMD sludge dose increased from low doses to $1.0 \mathrm{~g} / \mathrm{L}$, where an effluent concentration of 1.02 mg-P/L (equivalent to $95 \% \mathrm{P}$ removal) was achieved. When the sludge dose was increased above $1.0 \mathrm{~g} / \mathrm{L}$, the decrease in effluent $\mathrm{P}$ concentration was trivial (effluent concentration of $0.21 \mathrm{mg} / \mathrm{L}$ at a sludge dose of $2.0 \mathrm{~g} / \mathrm{L}$ ). Considering $20 \mathrm{mg}-\mathrm{P} / \mathrm{L}$ was a rather high concentration in wastewater effluent, the dose of $1.0 \mathrm{~g} / \mathrm{L}$ was used in subsequent adsorption tests, unless stated otherwise. The effect of contact time on effluent $\mathrm{P}$ concentration is shown in Fig. 1.2(b). In the first $5 \mathrm{~min}$, rapid phosphorus removal was observed and a $\mathrm{P}$ removal of $89 \%$ was determined. Thereafter, a gradual decrease in effluent $\mathrm{P}$ concentration occurred as mixing time was increased up to $1 \mathrm{hr}$. The effluent $\mathrm{P}$ concentration decrease was trivial after $1 \mathrm{hr}$ mixing, which suggested that the equilibrium of orthophosphate adsorption onto the AMD sludge particles had been reached. Consequently, $1 \mathrm{hr}$ mixing was used as the contact time in all further studies of adsorption at equilibrium. Similar results were found in the literature on the rapid 
adsorption rate of dyes using AMD sludge (Wei and Viadero, 2007) and fly ash (Acemioglu, 2004) as adsorbents.

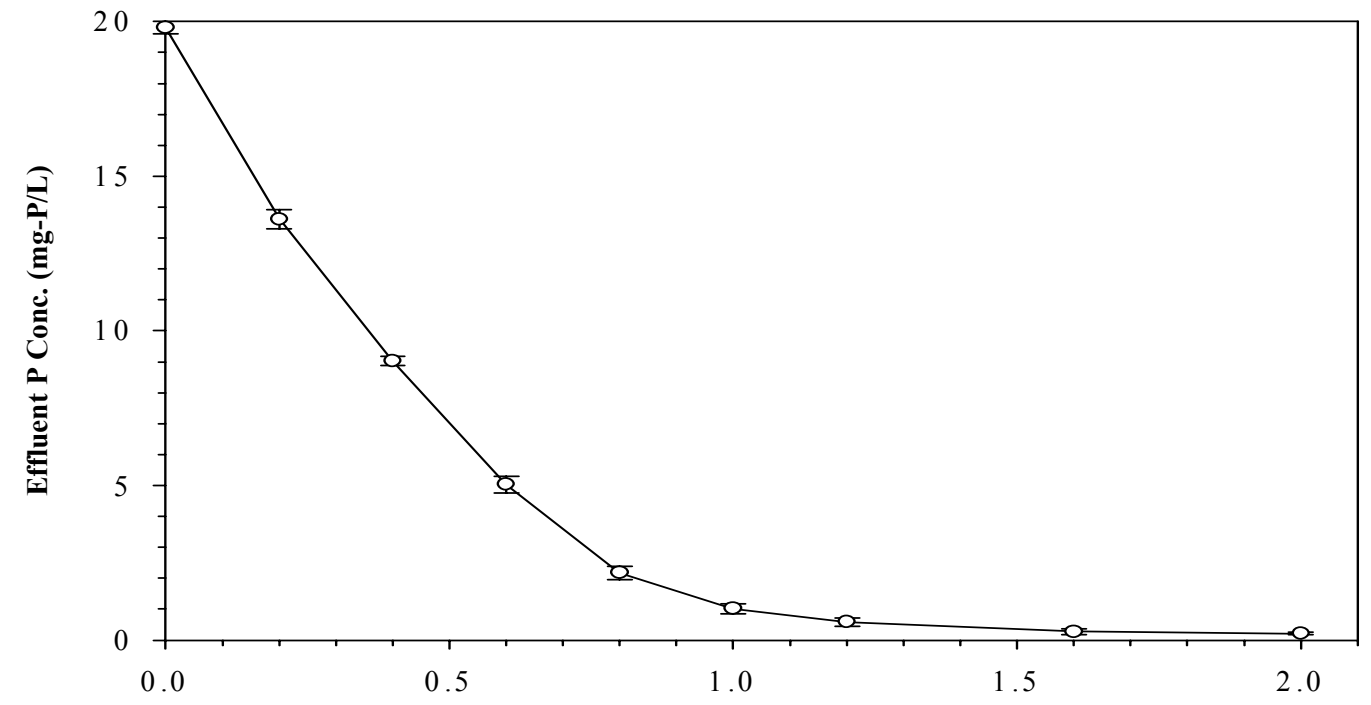

(a)

Sludge Dosage (g/L)

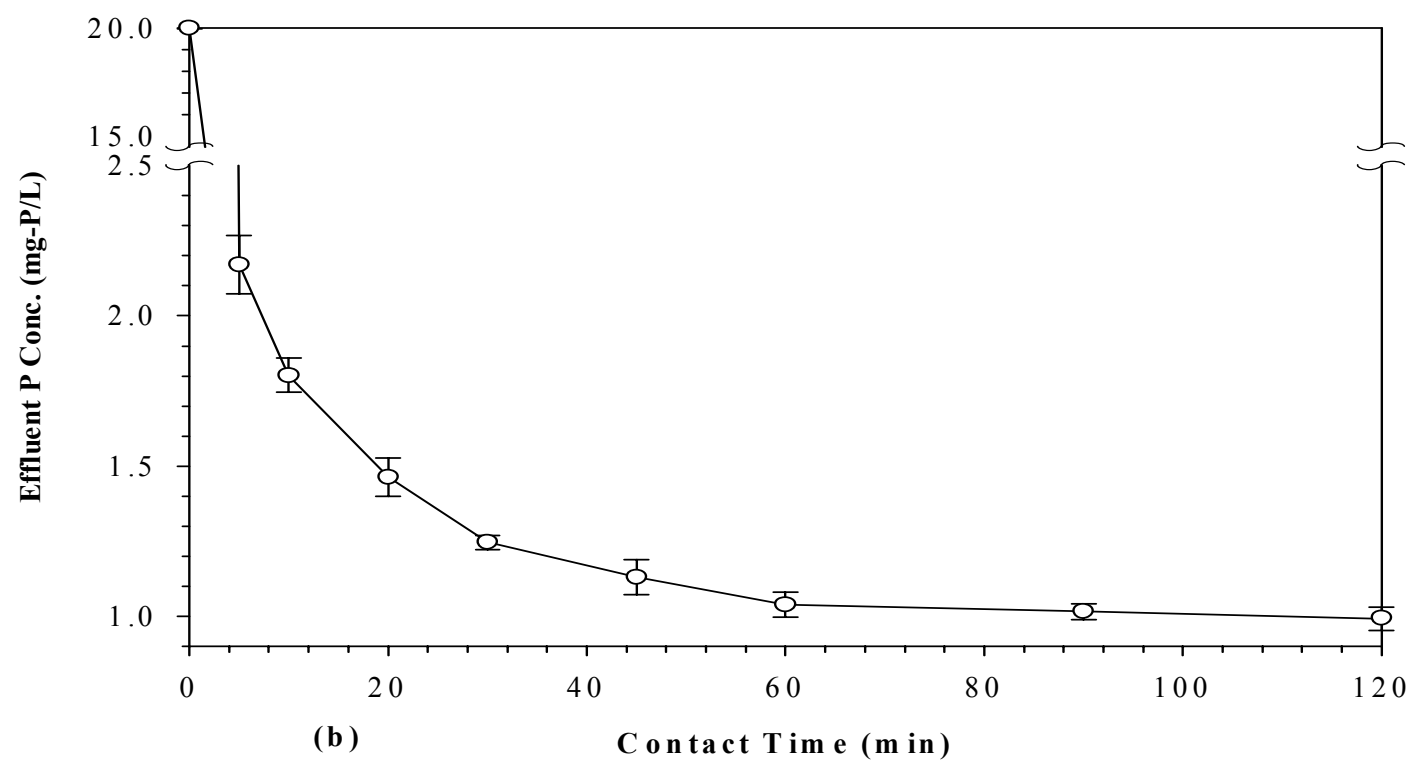

Figure 1.2 Effect of AMD sludge dosage and contact time on effluent $P$ concentration (mean \pm 1 standard deviation). (a) sludge dose (initial concentration $20 \mathrm{mg} \mathrm{P} / \mathrm{L} ; 20^{\circ} \mathrm{C} ; \mathrm{pH} 7.0 \pm 0.1$; mixing time $1 \mathrm{~h}$; dosage $0-2.0 \mathrm{~g} / \mathrm{L}$ ); (b) contact time (sludge dosage $1 \mathrm{~g} / \mathrm{L} ; 2^{\circ} \mathrm{C} ; \mathrm{pH} 7.0 \pm 0.1$; initial concentration $20 \mathrm{mg} \mathrm{P} / \mathrm{L}$ ). 


\subsubsection{Effect of pH, temperature and adsorption thermodynamics}

System $\mathrm{pH}$ during adsorption has a significant effect on the surface characteristics of the adsorbent particles, and consequently, overall adsorption performance. Illustrated in Fig. 1.3(a) is the effect of $\mathrm{pH}$ on effluent $\mathrm{P}$ concentration (sludge dose of $0.6 \mathrm{~g} / \mathrm{L}$ was used). It was observed that effluent $\mathrm{P}$ concentration increased with an increasing $\mathrm{pH}$, indicating orthophosphate adsorption by AMD sludge was inhibited at high $\mathrm{pH}$. The result was consistent with the $\mathrm{P}$ adsorption study using granulated ferric hydroxide (Genz et al., 2004). Thus, neutral or slightly acidic $\mathrm{pH}$ was indicated when using AMD sludge for the removal of dissolved phosphorus from solution. It should be noted that $\mathrm{pH}$ lower than 5 or greater than 8.5 was not examined due to concerns related to metal resolubilization.

Phosphorus removal using AMD sludge was essentially an anionic adsorption process. AMD sludge used in this study consisted mainly of iron and aluminum oxides/hydroxides. In aqueous solution, protonation and deprotonation might take place at the hydroxyl sites on the surface of metal hydroxides $(\mathrm{M}-\mathrm{OH})$, depending on the system $\mathrm{pH}$, which could result in a change of surface charges. The point of zero charge (PZC) of iron and aluminum hydroxides reported in the literature ranged from 8 to 9 (Cornell and Schwertmann, 2003; Sparks, 2003), indicating the surfaces of AMD sludge particles were positively charged at $\mathrm{pH}$ less than 8 , which would favor the adsorption of anionic orthophosphate ions. Improved adsorption at lower $\mathrm{pH}$ as shown in Fig. 1.3(a) provided further confirmation that adsorption was enhanced due to the attraction between the anionic phosphate ions and the positively changed surfaces of sludge particles. 

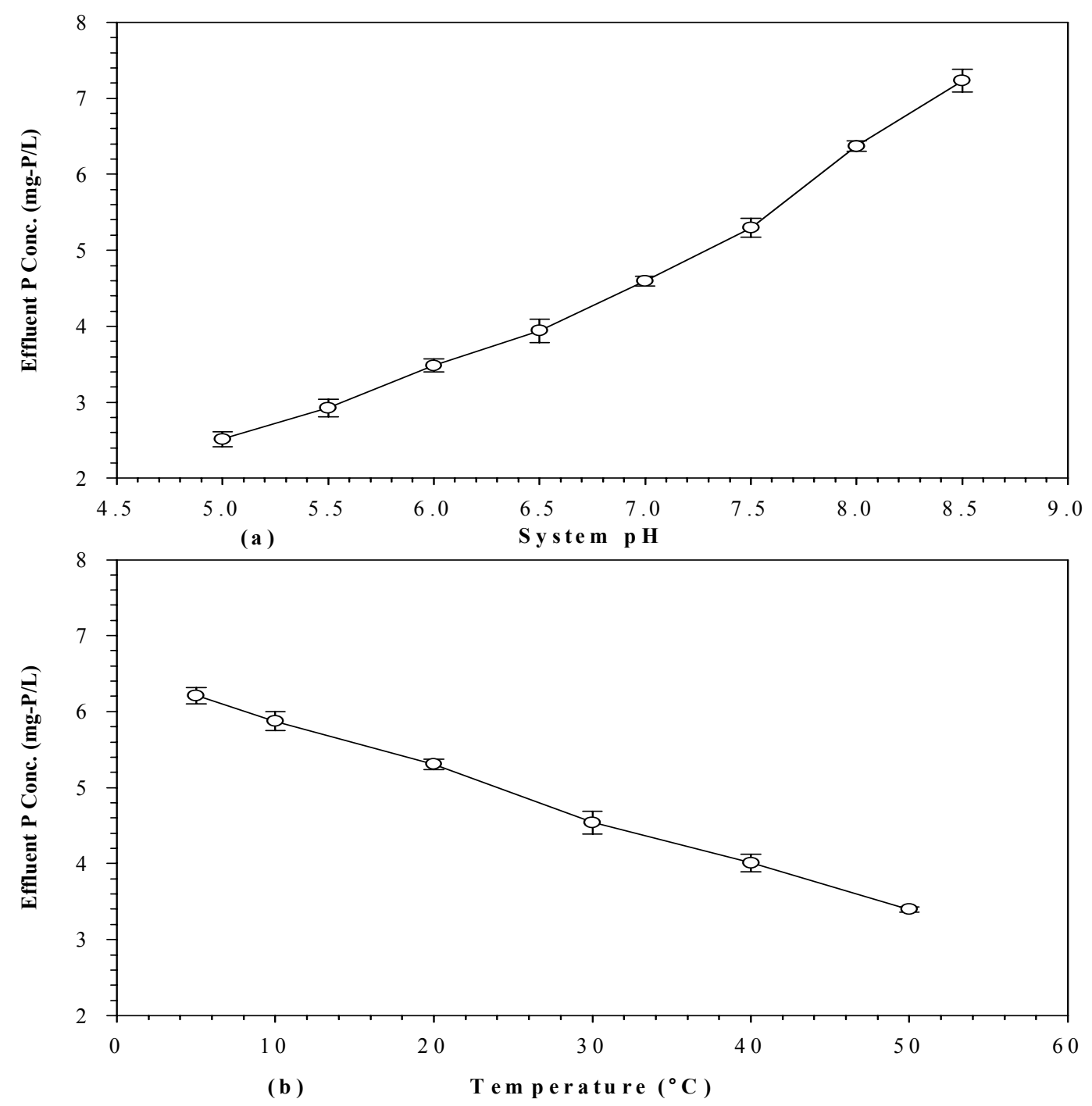

Figure 1.3 Effect of $\mathrm{pH}$ and temperature on effluent $\mathrm{P}$ concentration (mean \pm 1 standard deviation). (a) $\mathrm{pH}$ (initial concentration $20 \mathrm{mg} \mathrm{P/L}$; sludge dosage $0.6 \mathrm{~g} / \mathrm{L}$; miximg time $1 \mathrm{~h} ; 20^{\circ} \mathrm{C}$ ); (b) temperature (initial concentration $20 \mathrm{mg} \mathrm{P} / \mathrm{L}$; sludge dosage $0.6 \mathrm{~g} / \mathrm{L}$; mixing time $1 \mathrm{~h} ; \mathrm{pH} 7 \pm 0.1)$.

The effect of temperature on effluent $\mathrm{P}$ concentration is presented in Fig. 1.3(b). A decrease in effluent $\mathrm{P}$ concentration was observed at higher temperatures. Consequently, the amount of phosphorus adsorbed by AMD sludge increased with temperature. Thermodynamic studies, such as the change in standard free energy $\left(\Delta G^{0}\right)$, 
enthalpy $\left(\Delta H^{0}{ }_{a d s}\right)$, and entropy $\left(\Delta S^{0}\right)$ of adsorption, helped further clarify the effect of temperature on phosphorus adsorption. Gibbs free energy of adsorption $\left(\Delta G^{0}\right)$ was computed based on the equilibrium constant $\left(K_{c}\right)$ in the following equation:

$$
\Delta G^{0}=-R T \ln \left(K_{c}\right)
$$

where $R$ is the universal gas constant $(8.314 \mathrm{~kJ} / \mathrm{kmol} / \mathrm{K}), T$ is the adsorption temperature in Kelvin, and $K_{c}$ is equilibrium constant (ratio of the concentration of orthophosphate ions adsorbed by adsorbent to that of orthophosphate ions in the aqueous phase at equilibrium) (Namasivayam and Kavitha, 2002). The standard enthalpy $\left(\Delta H^{0}\right.$ ads $)$ and entropy $\left(\Delta S^{0}\right)$ were estimated from the van't Hoff equation (Eqn. 2) via linear regression (Acemioglu, 2004):

$$
\ln \left(K_{c}\right)=\frac{-\Delta H_{a d s}^{0}}{R T}+\frac{\Delta S^{0}}{R}
$$

The linear relationship between $\ln \left(K_{c}\right)$ and $1 / T$ for $\mathrm{P}$ adsorption was found and the determined thermodynamic parameters are presented in Table 1.2. The negative values of Gibbs free energy $\left(\Delta G^{0}\right)$ suggested the spontaneity of $\mathrm{P}$ adsorption process over the temperature range tested. Further, based on the positive value of $\Delta H^{0}$ ads, the adsorption reaction was found to be endothermic, which was in agreement with the improvement in phosphorus removal by AMD sludge at higher temperatures (Fig. 3(b)). However, this finding was different from that of synthetic dye adsorption by AMD sludge (Wei and Viadero, 2007), where adsorption was found to be exothermic. The positive $\Delta S^{0}$ indicated that adsorption of phosphorus onto AMD sludge particles resulted in an increase of randomness at the solid-liquid interface. 
Table 1.2 Thermodynamic parameters for $P$ adsorption by AMD sludge.

\begin{tabular}{rrrrr}
\hline \multirow{2}{*}{$\begin{array}{c}\text { Temperature } \\
\left({ }^{\circ} \mathrm{C}\right)\end{array}$} & $K_{c}$ & $\begin{array}{c}\Delta G^{0} \\
(\mathrm{~kJ} / \mathrm{mol})\end{array}$ & & \multicolumn{2}{c}{$\begin{array}{c}\Delta H_{\mathrm{ads}}^{0} \\
(\mathrm{~kJ} / \mathrm{mol})\end{array}$} & $\begin{array}{c}\Delta S^{0} \\
(\mathrm{~kJ} / \mathrm{mol} / \mathrm{K})\end{array}$ \\
\hline 5 & 2.22 & -6.63 & & \\
10 & 2.41 & -7.30 & & \\
20 & 2.77 & -8.47 & 12.99 & 0.053 \\
30 & 3.41 & -10.19 & & \\
40 & 3.99 & -11.50 & & \\
50 & 4.89 & -13.19 & & \\
\hline
\end{tabular}

\subsubsection{Adsorption isotherms}

Illustrated in Fig. 1.4 is the relationship between equilibrium effluent $\mathrm{P}$ concentration and adsorption capacity of AMD sludge. The adsorption capacity increased from $9.89 \mathrm{mg} / \mathrm{g}$ to $31.97 \mathrm{mg} / \mathrm{g}$ when the final effluent $\mathrm{P}$ concentration increased from $0.21 \mathrm{mg}-\mathrm{P} / \mathrm{L}$ to $13.61 \mathrm{mg}-\mathrm{P} / \mathrm{L}$. Based on these data, AMD sludge was found to have a $\mathrm{P}$ adsorption capacity comparable to or better than reported for other metal oxide adsorbents such as recovered ochre (Heal et al., 2004), granular ferric hydroxide (Genz et al., 2004), ferrihydrite (Kang et al., 2003), and synthetic AMD flocs (Adler and Sibrell, 2003).

The adsorption of $\mathrm{P}$ by AMD sludge was well described using the Freundlich isotherm (Eqn. 3).

$$
q_{e}=K C_{e}^{1 / n}
$$

where $C_{e}$ and $q_{e}$ are equilibrium $\mathrm{P}$ concentration in solution $(\mathrm{mg}-\mathrm{P} / \mathrm{L})$ and the corresponding $\mathrm{P}$ adsorption capacity of $\mathrm{AMD}$ sludge $(\mathrm{mg}-\mathrm{P} / \mathrm{g})$, and $K$ and $1 / n$ are empirical constants determined through regression analysis. As presented in Fig. 1.4, a 
linear relationship $\left(\mathrm{r}^{2}=0.953\right)$ between $q_{e}$ and $C_{e}$ was observed when the data were plotted on a log-log scale. The Freundlich constants $K$ and $1 / n$ were $17.0 \mathrm{mg}-\mathrm{P} / \mathrm{L}$ and 0.25 , respectively. Coincidentally, the outcomes of this isotherm study for P adsorption by AMD sludge were similar to those reported by Kang et al. (2003), who utilized ferrihydrite as an adsorbent for phosphorus removal $(K=19.4 \mathrm{mg}-\mathrm{P} / \mathrm{L}$ and $1 / n=0.29)$. The similarities between isotherm constants gives further support to the assertion that iron in ferrihydrite form was responsible for most of the P adsorption by AMD sludge.

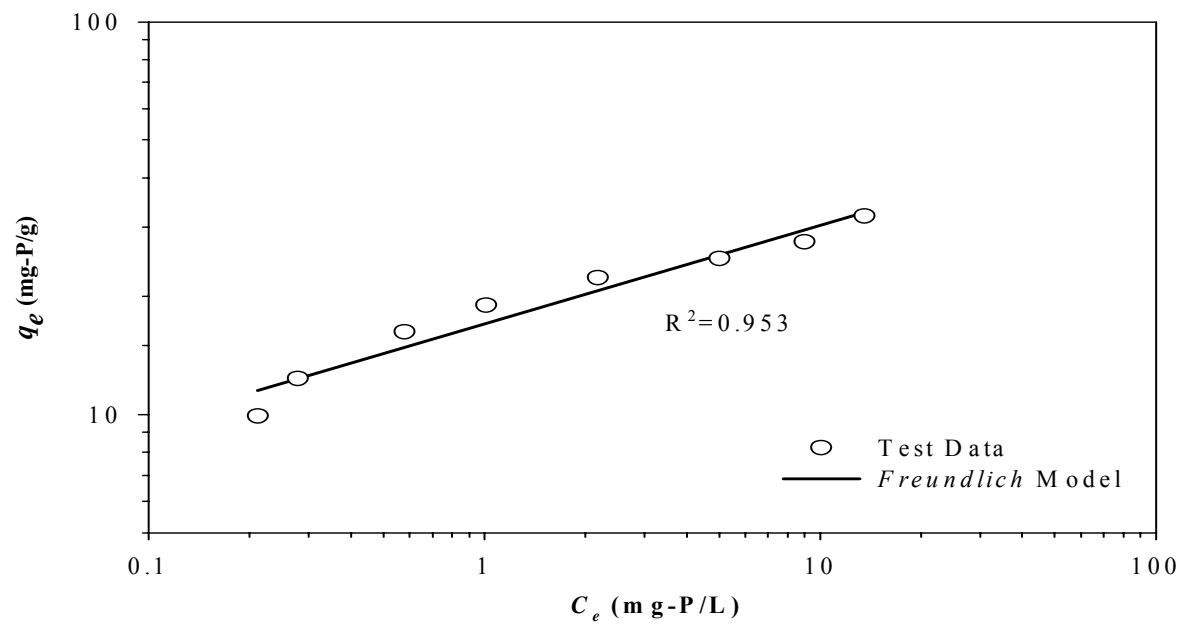

Figure 1.4 Freundlich isotherm of phosphorus adsorption by AMD sludge (mixing time $1 \mathrm{~h} ; \mathbf{2 0}^{\circ} \mathrm{C} ; \mathrm{pH}$ 7.0 \pm 0.1).

\subsubsection{Resolubilization of AMD sludge-bound metals}

Since AMD sludge resulted from the precipitation of dissolved metals as oxides/hydroxides, particular attention was paid to the potential for metal resolubilization due to $\mathrm{pH}$ changes or complexation reactions. Indeed, metal leaching from AMD sludge would limit the further value-added use of this byproduct from mine water treatment. The dissolved metal concentrations in the effluent of the adsorption process at $\mathrm{pH}$ ranging 
from 5 to 9 are presented in Table 1.3. When compared to experimental controls, some resolubilization of $\mathrm{Mn}$ at $\mathrm{pH}<6.0$ and $\mathrm{Al}$ at $\mathrm{pH}>8.0$ occurred. These observations were expected based on the solubility of Mn and Al hydroxides in water (Stumm and Morgan, 1996). At the tested $\mathrm{pH}$ range, no appreciable metal leaching was found for other metal elements. Consequently, it was concluded that metal resolubilization was not likely to be a major concern when phosphorus removal by AMD sludge was carried out at a $\mathrm{pH}$ range typical for municipal wastewater secondary effluents $(6<\mathrm{pH}<8)$.

Table 1.3 Dissolved metal concentrations $(\mathrm{mg} / \mathrm{L}$ ) in the effluents after $P$ adsorption by AMD sludge at different $\mathrm{pH}^{1}$ (initial concentration $20 \mathrm{mg}-\mathrm{P} / \mathrm{L}$; sludge dosage 1.0 g/L; mixing $1 \mathrm{hr} ; \mathbf{2 0}^{\circ} \mathrm{C}$ ).

$\mathrm{pH}$ variation: \pm 0.1 ;

\begin{tabular}{ccccccc}
\hline Metal & $\mathrm{Fe}$ & $\mathrm{Al}$ & $\mathrm{Mn}$ & $\mathrm{Cu}$ & $\mathrm{Ni}$ & $\mathrm{Zn}$ \\
\hline Control $^{2}$ & $<0.01$ & $<0.1$ & $<0.01$ & $<0.01$ & $<0.01$ & $<0.01$ \\
pH 5.0 & $<0.01$ & 0.1 & 0.24 & $<0.01$ & 0.05 & 0.04 \\
pH 6.0 & $<0.01$ & $<0.1$ & 0.14 & $<0.01$ & 0.02 & 0.01 \\
pH 7.0 & $<0.01$ & $<0.1$ & 0.01 & $<0.01$ & 0.01 & $<0.01$ \\
pH 8.0 & $<0.01$ & $<0.1$ & $<0.01$ & $<0.01$ & 0.01 & $<0.01$ \\
pH 9.0 & $<0.01$ & 0.3 & $<0.01$ & $<0.01$ & 0.02 & $<0.01$ \\
MDL $^{3}$ & 0.01 & 0.1 & 0.01 & 0.01 & 0.01 & 0.01 \\
\hline
\end{tabular}

${ }^{2}$ Control: P concentration $0 \mathrm{mg} / \mathrm{L}$; sludge dose $1.0 \mathrm{~g} / \mathrm{L} ; \mathrm{pH} \sim 8.1$;

${ }^{3}$ method detection limit.

\subsubsection{Continuous CSTR adsorption studies}

CSTR tests were conducted to develop insight into the potential of the AMD adsorption system for P removal from secondary effluents. The change in CSTR effluent P concentration over time for three different waters (synthetic wastewater, Mon River water, and secondary effluent from a POTW) is presented in Fig. 1.5(a). The P concentration decreased rapidly as CSTR testing started and P adsorption by the AMD 
sludge began to take place in the system. The CSTR system reached equilibrium in about $3 \mathrm{hr}$, based on the little change in effluent $\mathrm{P}$ concentration observed for $\mathrm{t}>3 \mathrm{hr}$. The equilibrium $\mathrm{P}$ concentration in the effluent was consistent with previous batch adsorption studies. The curves of effluent $\mathrm{P}$ concentration over time for the three types of water tested were in close agreement and in several instances were indistinguishable after 3 hours, indicating that phosphorus removal by AMD sludge was a rather robust process capable of treating wastewaters with varying characteristics. Although there were a variety of ionic species (anionic and cationic) present in the Mon River water and secondary effluent from the POTW (Table 1.1), the comparable adsorption performances for three types of water revealed that $\mathrm{P}$ adsorption by AMD sludge was relatively independent of the presence of other ionic species. Also presented in Fig. 1.5(a) are the $\mathrm{pH}$ changes during CSTR tests. The system $\mathrm{pH}$ reached equilibrium typically after $2 \mathrm{hr}$ operation, beyond which the system $\mathrm{pH}$ remained constant at 7.3, 7.7, and 7.8 for POTW effluent, Mon River water, and synthetic wastewater, respectively.

Hydraulic detention time, $\theta_{\mathrm{H}}$, is an important factor for CSTR operation, which may affect the treatment capacity for a tank with a certain dimension or its treatment effectiveness. In this study, detention times of $1 \mathrm{hr}$ and $2 \mathrm{hr}$ were tested. The change of $\mathrm{P}$ concentration in the effluent of CSTR over time using Mon River water dosed with orthophosphate stock solution to $20 \mathrm{mg}-\mathrm{P} / \mathrm{L}$ at different detention times is presented in Fig. 1.5(b). It was found that final effluent $\mathrm{P}$ concentrations at equilibrium were almost the same for hydraulic detention time at $1 \mathrm{hr}$ and $2 \mathrm{hr}$. Hydraulic detention time did not significantly affect phosphorus removal performance of AMD sludge, although it took a longer time to reach equilibrium at higher $\theta_{\mathrm{H}}$. This finding indicated that the CSTR 
process could be resilient in handling flow variation in full-scale processes if appropriate adjustments could be made to the AMD sludge dose. The system $\mathrm{pH}$ reached equilibrium after $2 \mathrm{hr}$ of operation and equilibrium $\mathrm{pH}$ for both hydraulic detention times was almost the same (pH 7.6 7.7, as shown in Fig. 1.5(b)).

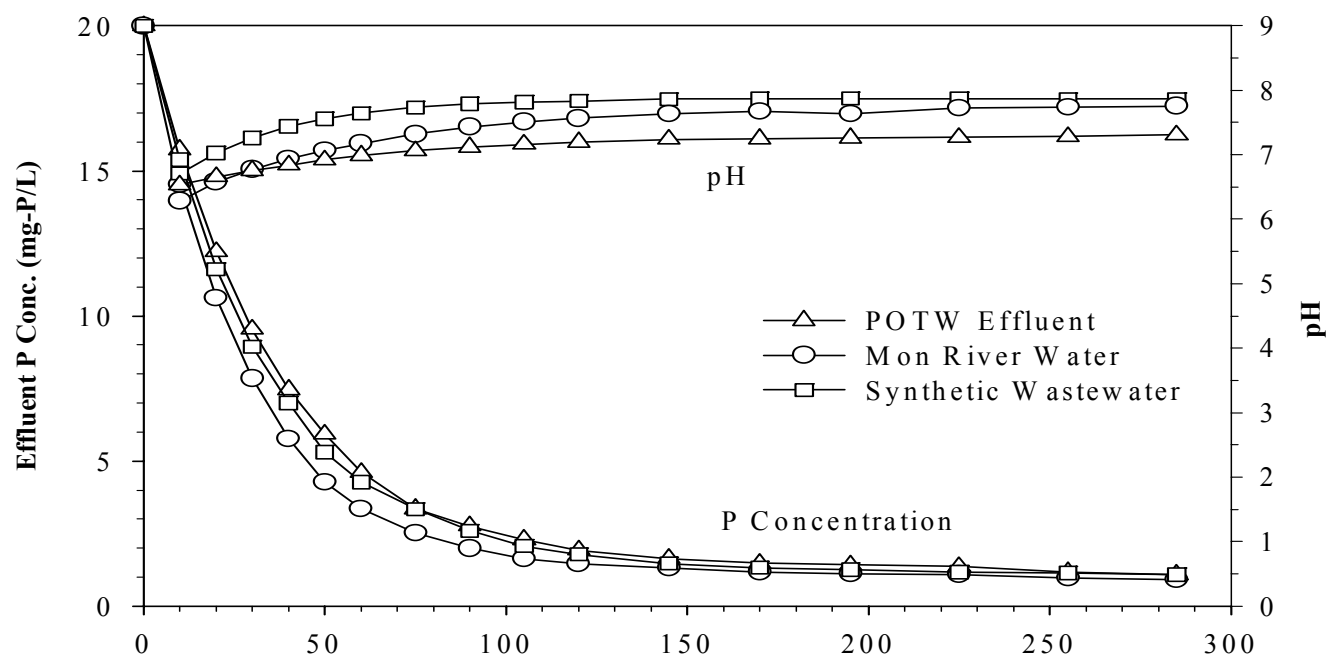

(a)

Time ( $m$ in )

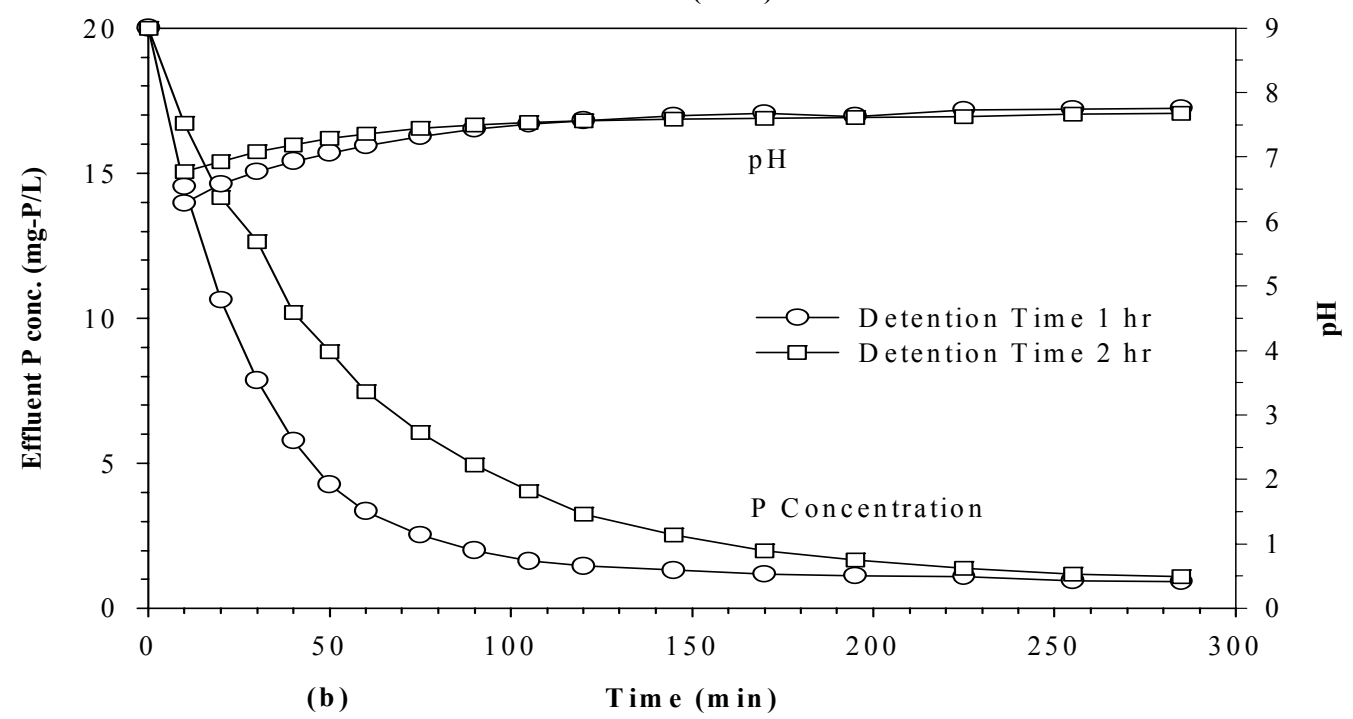

Figure 1.5 Change of effluent $P$ concentration and $\mathrm{pH}$ during CSTR tests. (a) Three types of water samples (feed rate $2 \mathrm{~L} / \mathrm{h}$; initial concentration $20 \mathrm{mg} \mathrm{P} / \mathrm{L}$; sludge dose $1 \mathrm{~g} / \mathrm{L}$; hydraulic detention time $1 \mathrm{~h} ; 2^{\circ} \mathrm{C}$ ); (b)detention time (Mon river water, feed rate 1 and $2 \mathrm{~L} / \mathrm{h}$; initial concentration $20 \mathrm{mg} P / \mathrm{L}$; sludge dose $1 \mathrm{~g} / \mathrm{L} ; 20^{\circ} \mathrm{C}$ ). 
In order to evaluate the proposed CSTR system for phosphorus removal from municipal wastewater effluent, an actual POTW effluent was tested at AMD sludge doses of $1.0,0.5$, and $0.35 \mathrm{~g} / \mathrm{L}$ ) without the addition of extra orthophosphate salts. The actual POTW effluent contained orthophosphate at a concentration of $1.80 \mathrm{mg}-\mathrm{P} / \mathrm{L}(9 \%$ of the $20 \mathrm{mg}-\mathrm{P} / \mathrm{L}$ dose applied in the previous CSTR tests). Presented in Fig. 1.6 is the change of effluent P concentration during CSTR tests at three AMD sludge doses for the POTW effluent. It was observed that higher AMD sludge doses resulted in lower effluent $\mathrm{P}$ concentrations. This trend was in agreement with observations from the batch adsorption tests conducted using the synthetic wastewater. The final effluent $\mathrm{P}$ concentrations at sludge doses of $1.0,0.5$, and $0.35 \mathrm{~g} / \mathrm{L}$ were $0.013,0.027$, and $0.034 \mathrm{mg} / \mathrm{L}$, respectively (equivalent to phosphorus removal of $99.3 \%, 98.5 \%$, and $98.1 \%$ ). Consequently, it was concluded that CSTR process could be used for phosphorus removal from secondary effluents by using AMD sludge as adsorbent.

Also presented in Fig. 1.6 is the $\mathrm{pH}$ change during CSTR tests using POTW effluent. The equilibrium $\mathrm{pH}$ ranged from 7.3 to 7.6. Slightly higher $\mathrm{pH}$ was observed at higher sludge doses due to the fact that the AMD sludge contained a mixture of metal oxides/hydroxides with a higher initial $\mathrm{pH}(\sim 8.1)$. 


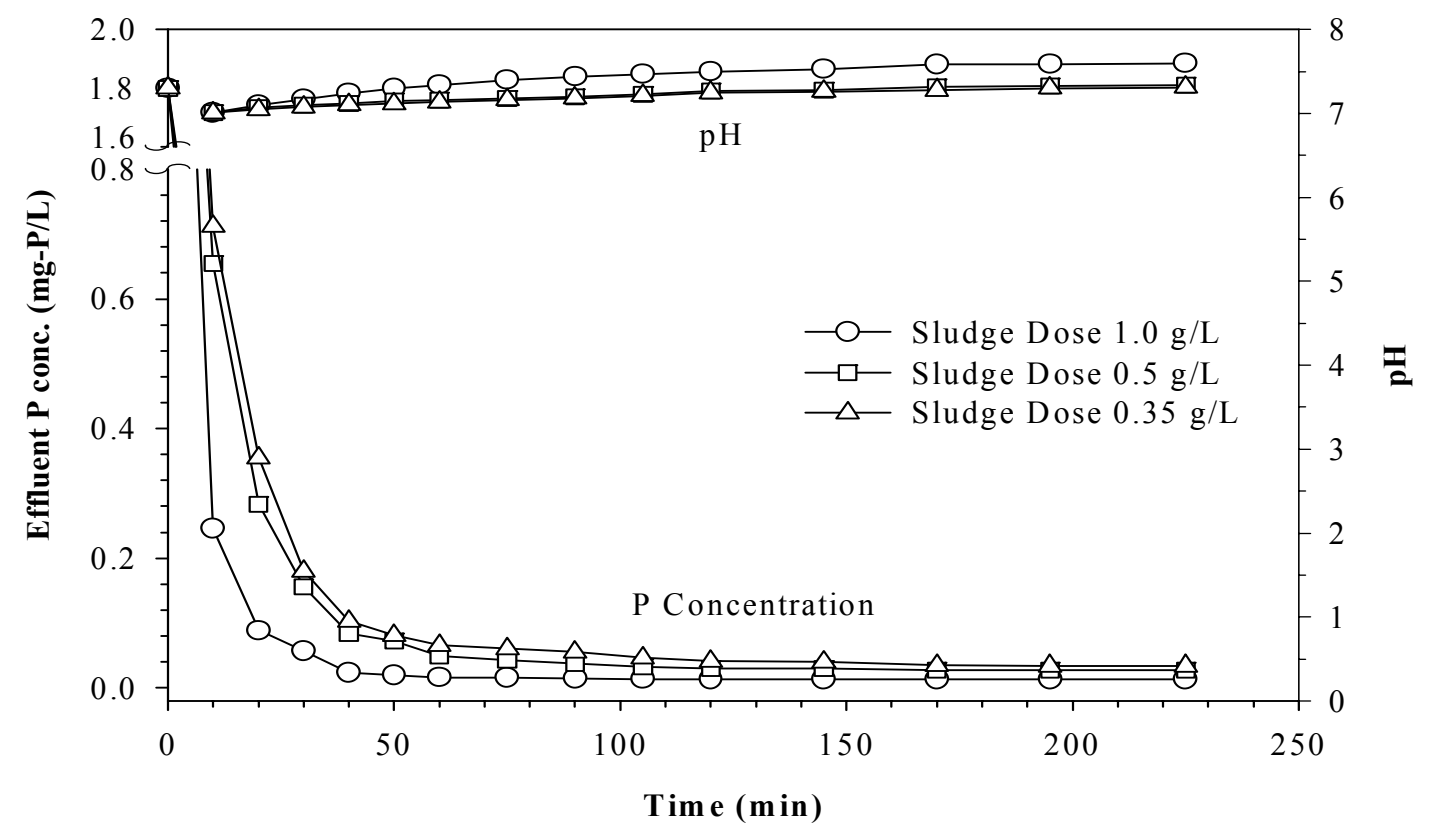

Figure 1.6 Change of effluent $P$ concentration and $\mathrm{pH}$ during CSTR tests at different AMD sludge doses for actual POTW effluent (feed rate 2L/h; hydraulic detention time $1 \mathrm{~h}$; initial concentration $1.8 \mathrm{mg} \mathrm{P} / \mathrm{L}$; sludge dose $1.0 \mathrm{~g} / \mathrm{L} ; 20^{\circ} \mathrm{C}$ ).

\subsubsection{Implication for nutrient removal from municipal wastewater effluents}

Eutrophication due to excess nutrient (especially P) loading in receiving waters is a worldwide problem with significant adverse consequences for the environmental and and economic futures of developed and developing nations. Consequently, the control of nutrient loading has become a high priority for environmental regulatory agencies of many countries. In particular, it is known that POTWs contribute most to point-source nutrient loading. Although newer technologies do exist for the removal of nutrients from POTW effluents, they typically involve extensive capital investment and increased operation costs which often cannot be met - particularly in the developing world. Consequently, cost-effective technologies for nutrient removal are urgently needed. 
The use of AMD sludge is very promising for P removal from POTW effluents. The process could be implemented as a CSTR-based unit operation tertiary treatment for secondary effluents. A process flow diagram is presented in Fig. 1.7(a \& b) for a typical suspended growth wastewater treatment system and a system modified for tertiary treatment using AMD sludge adsorption. After secondary treatment, P-containing secondary effluent enters a CSTR containing AMD sludge. After phosphorus adsorption in the CSTR, the AMD sludge laden with orthophosphate can be recovered from the effluent using a variety of solid/liquid separation processes.

A second method to implement AMD sludge to remove P from POTW effluents is through the injection and complete mixing of AMD sludge with the primary effluent, prior to secondary treatment, as presented in Fig. 1.7(c). In this approach, there is no need for capital cost intensive tertiary treatment. However, a number of key factors must be examined prior to implementing this approach. For instance, the potential effects of AMD sludge on biological processes in secondary treatment are unknown. Likewise, the presence of AMD sludge in secondary treatment processes may require changes to solid/liquid separation processes and could have effects on the further beneficial use (e.g., land application) of biosolids recovered from suspended growth systems.

Beneficial use of waste materials for pollutants removal from wastewater is a practical approach to environmental sustainability. After the adsorption capacity of AMD sludge is exhausted, the resulting P-enriched sludge could then potentially be used as a fertilizer (Dobbie et al., 2005), indicating a value-added final disposal option for AMD sludge. Although the resolubilization of metals from AMD sludge was not a major concern in this study, the variable chemical characteristics of AMD sludge from different 
sites and the potential presence of toxic elements could limit the full-scale application of the proposed process (Hancock, 2005).

Wet AMD sludge with low solids content (4.31\%) was tested to take full advantage of the high surface area and active sites of sludge particles. However, it could be costly and impractical to transport AMD sludge with low solids to municipal wastewater treatment facilities, which might necessitate sludge mechanical dewatering or air-drying at AMD treatment sites (Heal et al., 2004). Consequently, the scale up of the proposed process requires further technical demonstration in pilot field studies to fully assess the effects of variability of sludge sources, operational practicalities, waste disposal, treatment cost-benefit tradeoff, and related regulatory issues. 

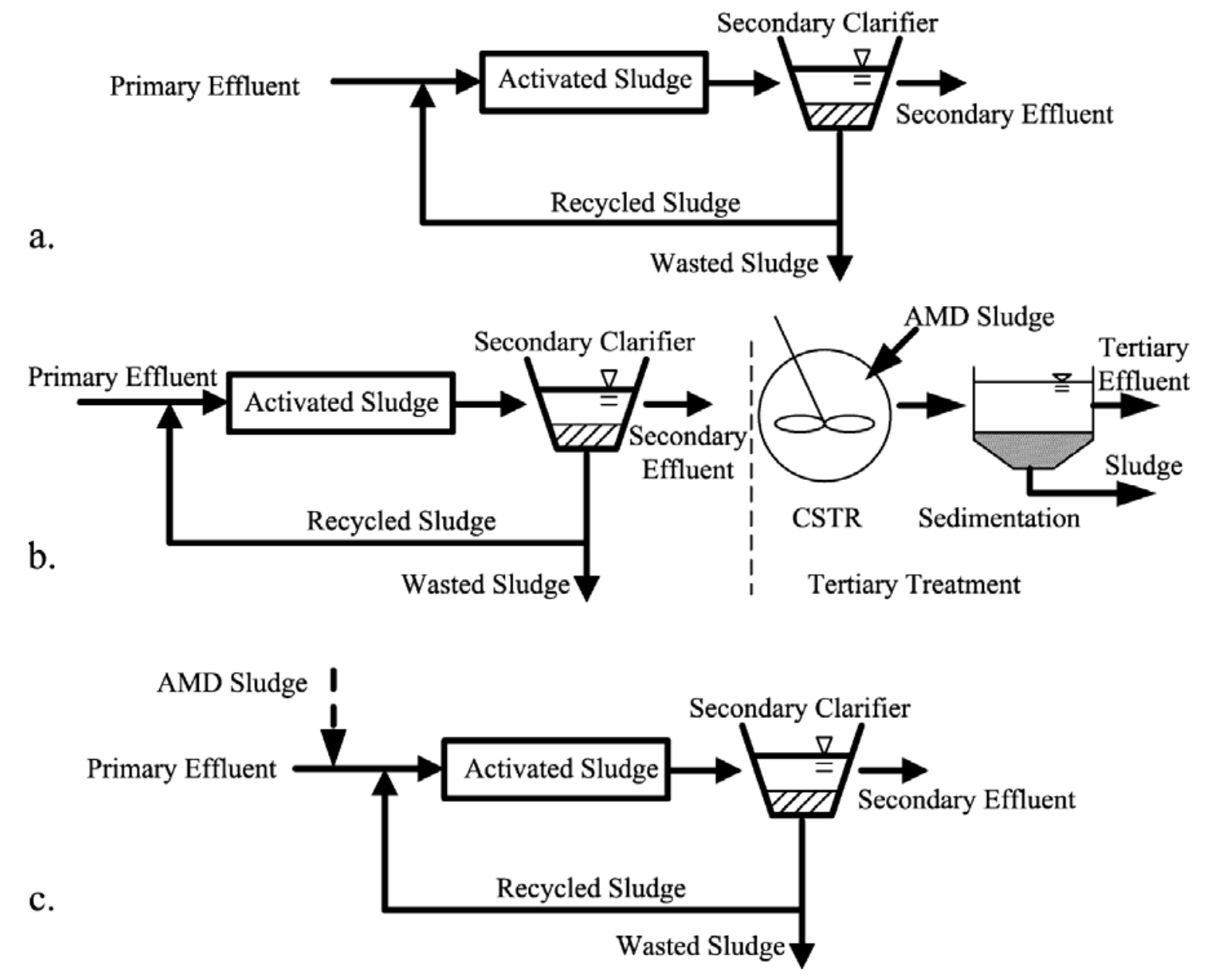

Figure 1.7 Proposed process for phosphorus removal using AMD sludge (a) typical suspended growth secondary treatment; (b) AMD sludge adsorption tertiary treatment added to a typical suspended growth system; and (c) integration of AMD sludge-based adsorption into secondary treatment. 


\subsection{Conclusions}

The effective control of phosphorus release from municipal wastewater effluents into surface waters is known to be an effective and practical approach to decreasing eutrophication in receiving waters. Batch and continuous adsorption experiments demonstrated that a waste sludge, generated from acid mine water treatment, was very promising as an adsorbent to remove phosphorus from wastewater. Phosphorus removal was found to be a beneficial use of AMD sludge prior to its final disposal. Adsorption of orthophosphate onto AMD sludge particles followed the Freundlich isotherm model with an adsorption capacity ranging $9.89 \mathrm{mg} / \mathrm{g}$ to $31.97 \mathrm{mg} / \mathrm{g}$ when the final effluent concentration increased from $0.21 \mathrm{mg}-\mathrm{P} / \mathrm{L}$ to $13.61 \mathrm{mg}-\mathrm{P} / \mathrm{L}$. In treating actual POTW effluent with a $\mathrm{P}$ concentration of $1.80 \mathrm{mg}-\mathrm{P} / \mathrm{L}$ in a continuous flow system, phosphorus removal efficiency of above $98 \%$ was obtained. The process showed potential to be used as a tertiary treatment for the secondary effluents to address P-related eutrophication problems. However, pilot studies are necessary in order to develop a full-scale process for efficient, cost-effective phosphorus removal. 


\section{References}

Acemioglu, B. (2004). "Adsorption of Congo Red from aqueous solution onto calcium rich fly ash.” J. Colloid Interface Sci., 274(2), 371-379.

Ackman, T. (1982). "Sludge disposal from acid mine drainage treatment." Report of Investigation 8672, US Bureau of Mines, Pittsburgh.

Adler, P.R., Sibrell, P.L. (2003). "Sequestration of phosphorus by acid mine drainage floc.” J. Environ. Qual., 32(3), 1122-1129.

APHA. (1998). "Standard methods for the examination of water and wastewater." $18^{\text {th }}$ Ed., American Public Health Association, Washington, DC.

Arias, M., Da Silva-Carballal, J., Garcia-Rio, L., Mejuto, J., Nunez, A. (2006). "Retention of phosphorus by iron and aluminum-oxides-coated quartz particles." $J$. Colloid Interface Sci., 295(1), 65-70.

Cornell, R.M., Schwertmann, U. (2003). "The iron oxides: structure, properties, reactions, occurrences and uses." Wiley-VCH GmbH\&Co. KGaA, Weinheim.

De-Bashan, L.E., Bashan, Y. (2004). "Recent advances in removing phosphorus from wastewater and its future use as fertilizer (1997-2003).” Water Res., 38(19), 42224246.

Dempsey, B.A., Roscoe, H.C., Ames, R., Hedin, R., Jeon, B.-H. (2001). "Ferrous oxidation chemistry in passive abiotic systems for treatment of mine drainage." Geochemistry: Exploration, Environment, Analysis 1(1), 81-88.

Dobbie, K.E., Heal, K.V., Smith, K.A. (2005). "Assessing the performance of phosphorus-saturated ochre as a fertiliser and its environmental acceptability." Soil Use Manage., 21, 231-239. 
Duenas, J.F., Ribas, Alonso J.R., Rey, A.F., Ferrer, A.S. (2003). "Characterisation of phosphorus forms in wastewater treatment plants." J. Hazard. Mater., 7(1-3), 193205.

Edwards, A.C., Withers, P.J.A.(2007). "Linking phosphorus sources to impacts in different types of water body". Soil Use Manage., 23, 133-143.

Galarneau, E., Gehr, R. (1997). "Phosphorus removal from wastewaters: Experimental and theoretical support for alternative mechanisms." Water Res., 31(2), 328-338.

Genz, A., Kornmuller, A., Jekel, M. (2004). "Advanced phosphorus removal from membrane filtrates by adsorption on activated aluminum oxide and granulated ferric hydroxide." Water Res., 38(16), 3523-3530.

Hancock, S. (2005). "Quantifying ochre arisings: output from the UK Coal Authority's mine water treatment sites, in Mine Water 2005 - Mine Closure." Proceedings of the 9th International Mine Water Association Congress, Oviedo, Spain, 5-7 September, 2005, pp. 395-402.

Havens K.E., Schelske C.L. (2001). “The importance of considering biological processes when setting total maximum daily loads (TMDL) for phosphorus in shallow lakes and reservoirs." Environ. Pollut., 113(1), 1-9.

Heal, K.V., Smith K.A., Younger, P.L., McHaffie, H., Batty, L.C. (2004). "Removing P from sewage effluent and agricultural runoff using ochre recovered from mine water treatment. In: Valsami-Jones, E. (Ed.) Phosphorus in Environmental Technology: removal, recovery and applications." IWA Publishing, London, pp. $320-334$. 
Johnson, D.B., Hallberg, K.B. (2005). "Acid mine drainage remediation options: A review." Sci. Total Environ., 338(1-2), 3-14.

Kang, S.-K., Choo, K.-H., Lim, K.-H. (2003). "Use of iron oxide particles as adsorbents to enhance phosphorus removal from secondary wastewater effluent." Separ. Sci. Technol., 38(15), 3853-3874.

Kirby, C.S., Decker, S.M., Macander, N.K. (1999). "Comparison of color, chemical and mineralogical compositions of mine drainage sediments to pigment." Environ. Geol., 37, 243-254.

Kuyucak, N. (1998). "Mining, the environment and the treatment of mine effluent. "Int. J. Environ. Pollut., 10(2), 315-325.

Matlock, M.M., Howerton, B.S., Atwood, D.A. (2002). "Chemical precipitation of heavy metals from acid mine drainage.” Water Res., 36, 4757-4767.

Morse, G.K., Brett, S.W., Guy, J.A., Lester, J.N. (1998). "Review: phosphorus removal and recovery technologies." Sci. Total Environ., 212(1), 69-81.

Namasivayam, C., Kavitha, D. (2002). "Removal of Congo Red from water by adsorption onto activated carbon prepared from coir pith, an agricultural solid waste." Dyes Pigments 54(1), 47-58.

Oleszkiewicz, J.A., Barnard, J.L. (2006). "Nutrient removal technology in North America and the European Union: A review." Water Qual. Res. J. Can., 41(4), 449-462.

Selig, U., Hubener, T., Michalik, M. (2002). "Dissolved and particulate phosphorus forms in a eutrophic shallow lake." Aquat. Sci., 64(1), 97-105.

Sparks, D. L. (2003). "Environmental soil chemistry", $2^{\text {nd }}$ Ed., Academic Press, Boston. 
Stumm, W., Morgan, J.J. (1996). “Aquatic chemistry”, John Wiley \& Sons, Inc., New York.

Viadero, Jr., R.C., Wei, X., Buzby, K.M. (2006). "Characterization and dewatering evaluation of acid mine drainage sludge from ammonia neutralization." Environ. Eng. Sci., 23(4), 734-743.

Walker, Jr., W.W. (2003). "Consideration of variability and uncertainty in phosphorus total maximum daily loads for lakes." J. Water Resour. Plann. Manage., 129(4), 337-344.

Wei, X., Viadero Jr., R.C., Buzby, K.M. (2005). "Recovery of iron and aluminum from acid mine drainage by selective precipitation.” Environ. Eng. Sci., 22(6), 745-755.

Wei, X., Viadero, Jr. R.C. (2007). "Adsorption and precoat filtration studies of synthetic dye removal by acid mine drainage sludge." J. Environ. Eng., 133(6), 633-640.

Yang, Y., Tomlinson, D., Kennedy, S., Zhao, Y.Q. (2006). "Dewatered alum sludge: A potential adsorbent for phosphorus removal." Water Sci. Technol., 54(5), 207-213. 


\section{CHAPTER 2: REMOVAL OF SELENIUM FROM AQUEOUS SOLUTIONS BY NANO-MAGNETITE}

\subsection{Introduction}

Selenium (Se) is a metalloid element belonging to the Group XVI of the periodic table. It occurs naturally in the environment though it is among the rare elements on the surface of the earth. Selenium is widely, but unevenly distributed in rocks, plants, coals and other fossil fuels (Suvardhan et al., 2005). Selenium is mostly found in rocks with sulfide minerals or with silver, nickel, lead and copper minerals. In the atmosphere, selenium is present as its methyl derivatives. Selenium has good photovoltaic and photoconductive properties, and is extensively used in electronics, such as photocells, light meters and solar cells. The second largest use of selenium is in the glass industry and the third greatest use, accounting for $15 \%$, is sodium selenite for animal feeds and food supplements (Lenntech, 2008). Selenium is an essential micronutrient for humans and animals, either in inorganic or organic forms. However, selenium is considered toxic when ingested in amounts higher than those needed for optimum nutrition. Selenium uptake through food is usually enough to meet human needs. In case of deficiency, people may experience heart and muscle problems. Depending on the periods of exposure (acute, 14 days; intermediate, 15-364 day; and chronic, 365 days or more) and routes of exposure (inhalation, dermal and oral), the health effects on humans could be systemic, immunological, neurological, reproductive, developmental, genotoxic and carcinogenic (U.S Dept of Health and Human Services, 2001). 
In addition to its natural occurrence in the environment, selenium can be released anthropogenically, making its way into the food chain. Selenium in the aquatic environment can bioaccumulate and reach toxic levels to fish and wildlife. In terms of Se speciation, Selenium can exist in four different oxidation states viz., elemental selenium $\left(\mathrm{Se}^{0}\right)$, selenite $\left(\mathrm{SeO}_{3}{ }^{2-}\right)$, selenide $\left(\mathrm{Se}^{2-}\right)$, selenate $\left(\mathrm{SeO}_{4}{ }^{2-}\right)$ (Parida et al., 1996) and the mobility of selenium is largely dependent on the availability of the aforementioned species. The more soluble and mobile forms are selenites and selenates (Bennett, 1983; Sharmasarkar et al., 2001). Temperature, moisture, organic matter and microbiological activity usually dictate how fast selenium is transported through soil and later into surface waters, resulting in an increased chance of human exposure.

According to the Superfund Amendments and Reauthorization Act (SARA), Section 313, Toxic Release Inventory (TRI99 2001), an estimated total of 338,004 pounds of selenium metal was released to air, water, land or injected underground from manufacturing and processing facilities in the United States in 1999 (U.S Dept of Health and Human Services, 2001). Industries which can cause Se release in their wastes include coal mining and combustion, gold, silver and nickel mining, metal smelting, municipal landfills, oil transport, refining and utilization and agricultural irrigation (Lemly, 2004). In particular, mining operations and subsequent processing and utilization of coal and minerals result in the release of selenium as selenite oxyanions $\left(\mathrm{SeO}_{3}{ }^{2-}\right)$ into wastewater and mine drainage (Adams and Pennington, 2005), posing a great ecological and environmental risk. The most dominant forms of selenium in coal are sulfidic and organic although silicate forms could also exist (Yudovich and Ketris, 2005). The predominant Se species in oxidized and alkaline soils such as surface coal mine soils is selenate which 
can be transformed into selenite under reducing conditions, a form that predominates in acidic or neutral soils. The anthropogenic disturbance of waste soil piles can release toxic levels of Se into the environment (Sharmasarkar et al., 2001). Consequently, the exact characteristics of Se-containing water or wastewater depend on the source of Se, the transport pathways, and the environmental conditions (especially the redox conditions).

Worldwide regulations on selenium vary from country to country. In drinking water, most countries adopt the World Health Organization (WHO) Guidelines for Drinking-water Quality (WHO, 2003) which is $10 \mu \mathrm{g} / \mathrm{L}$ for Se. In the US, the Environmental Protection Agency (EPA) set both the maximum contaminant level (MCL) and the maximum contaminant level goal (MCLG) at $50 \mu \mathrm{g} / \mathrm{L}$ in the $1974 \mathrm{Safe}$ Drinking Water Act. The EPA believes, given present technology and resources, this is the lowest level to which water systems can reasonably be required to remove this contaminant should it occur in drinking water. In surface water, selenium is one of the priority toxic pollutants according to the Clean Water Act (CWA). The water quality criteria for acute aquatic freshwater and chronic aquatic freshwater are $20 \mu \mathrm{g} / \mathrm{L}$ and 5 $\mu \mathrm{g} / \mathrm{L}$, respectively. Although most drinking water sources tested in the United States have very low levels of selenium, around $10 \mu \mathrm{g} / \mathrm{L}$ in $99.5 \%$ of those tested (U.S. Dept.of Health \& Human Services, 2001); selenium levels exceeding the freshwater criterion can pose a serious risk to aquatic life and humans due to the likelihood of bioaccumulation in the food chain.

Selenium has long been recognized in the coal bearing stratigraphy in the Appalachian basin of the eastern United States. Se in streams draining areas disturbed by surface mining of coal in the central Appalachian basin was higher (median $12 \mu \mathrm{g} / \mathrm{L}$ ) in 
comparison to streams draining undisturbed areas (median $1.5 \mu \mathrm{g} / \mathrm{L}$ ) (Neuzil et al., 2007). Surface mining practices in West Virginia have recently caused considerable controversy due to the environmental, economical and societal impacts related to Se contamination. According to the WV Geological and Economic Survey (WVGES) toxic elements such as arsenic, mercury, lead and selenium are present in West Virginia coals. Although they occur in very low concentration, the adverse impacts of these toxic elements can be significant because million of tons of coal are mined and utilized each year (WVGES, 2005). High concentrations of selenium were discovered in West Virginia rivers downstream of mountaintop mining operations in 2003 (Renner, 2005). According to the West Virginia Department of Environmental Protection WVDEP 303(d) impaired water listing, over 30 streams and reaches in West Virginia are impaired by selenium, affecting a total length of 160 miles (WV DEP, 2008).

In order to mitigate the negative impact, address the increasing public concerns, and meet the more stringent environmental regulations, removal of selenium from aqueous phase, either as selenate or selenite, has been a focus of many recent studies with an aim to develop cost-effective processes. Among the technologies being investigated to remove selenium from water and wastewater, some are conventional methods that have been in practice for many years; some are novel and becoming more common or partially applied, while others are the area of emphasis of current ongoing research. In summary, the technologies involved in removing selenium from aqueous solution include:

a) Conventional water treatment practices. These technologies include lime neutralization/softening and ferric coagulation/flocculation. They are commonly used for treating selenium-bearing drinking water and groundwater. The drawback of these 
technologies is that the residual selenium concentrations are higher than regulation limits, and they generate large volumes of Se-containing sludge (Mavrov et al., 2006; Tidwell, 2005).

b) Se precipitation. Se can be removed via precipitation in the form of selenites, selenates, metal selenides or elemental selenium. However, it is ineffective as a mine water treatment technology because of the relatively high solubility of the precipitates as a function of $\mathrm{pH}$ (Tidwell, 2005). The solubilities increase with rise in $\mathrm{pH}$.

c) Ion exchange and membrane processes. These technologies involve reverse osmosis, nanofiltration, and emulsion liquid membranes. Ion exchange for selenium removal is reported to be more effective for selenite rather than selenate (Tidwell, 2005) and high amounts of total dissolved solids and high amounts of other anions (mainly sulfate) interferes greatly with the selenium removal. Reverse osmosis and nanofiltration techniques are rather uncommon because pre-treatment of water for both these methods is complicated (Mavrov et al., 2006). Emulsion liquid membrane is preferential in removing sulfate instead of selenate and is pH dependent (Mavrov et al., 2006; Tidwell, 2005).

d) Se Reduction. Selenate can be reduced to selenite using ferrous hydroxide with the latter being easier to remove and hence is used in treating surface and agricultural waters; however generation of large volumes of sludge, high cost of reagents and interferences by dissolved oxygen and other anions are factors that influence the wide application of this technique (Mavrov et al., 2006).

e) Biological processes. Removing selenium biologically has received great attention in recent times and is being studied greatly although long operating times and size of bioreactors are obvious challenges to be met (Mavrov et al., 2006). 
f) Adsorption processes. Adsorption is by far the most researched and most promising method in treating selenium laden waters and wastewaters. Adsorbents being studied for Se removal include alumina, activated carbon, (Tidwell et al., 2005), manganese nodule leached residues (Dash et al., 2006), sulphuric acid-treated peanut shell (Shafey, 2007) and various iron oxides/hydroxides. The iron-based adsorbents examined in selenium adsorption studies include amorphous iron oxyhydroxide (Benjamin, 1983; Balistrieriand Chao, 1990; Parida et al., 1997), goethite (Zhang and Sparks, 1990), ferrihydrite (Parida et al., 1997), 'waste' iron (III) hydroxide (Namasivayam et al, 2005), zerovalent iron(Zhang et al., 2005), hematite and magnetite (Martinez et al., 2006), crushed granite (Jan et al., 2007), goethite and hematite (Rovira et al., 2008), and iron-coated granular activated carbon (Zhang et al., 2008). The major drawbacks involved in using the above mentioned materials are preferential adsorption of either selenium species $\mathrm{Se}(\mathrm{IV})$ or $\mathrm{Se}(\mathrm{VI})$ and interferences by anions such as phosphate, vandate, etc.

Nanotechnology is a cross-discipline field with a revolutionary potential for improving environmental quality and sustainability through pollution prevention, treatment, and remediation. Nanoparticles are particles that have at least one dimension of $100 \mathrm{~nm}$ or less. The widespread use of nanoparticles with respect to remediation of environmental contaminants stems from the fact that the properties of many conventional materials change when the size is reduced to nanometers because nanoparticles have greater surface area per weight $\left(\sim 1000 \mathrm{~m}^{2} / \mathrm{g}\right)$ and therefore are more reactive to certain molecules. While the application of nanotechnology is promising, the associated high costs and the potential consequences of nanoparticles on public health are limiting factors. Consequently, low-cost, environmentally friendly nano-materials are the focus of 
many recent research efforts in environmental treatment or remediation. Among them, nano-magnetite has received significant attention because it is relatively inexpensive, safe, and environmentally friendly with broad applications such as ferrofluid technology, magnetic storage, and environmental protection. Nano-sized magnetite as a novel nanomaterial has been examined as an adsorbent to remove such contaminants as $\mathrm{Cr}^{6+}(\mathrm{Hu}$ et al., 2004), methylene blue (Mak and Chen, 2004), and $\mathrm{Cu}, \mathrm{Zn}$, As and dichlorophenol (Cumbal and SenGupta, 2005) from aqueous solutions. However, no research was found in the literature on selenium removal with nano-magnetite.

Consequently, the objective of this study was to develop a nano-adsorption process using nano-magnetite to remove selenium from water and wastewater. Although the primary focus of this study was to remove selenite, which is the more mobile and readily transported species in groundwater, the adsorption of selenate was also investigated. In order to compare the effectiveness of magnetite as a nano-adsorbent, natural magnetite (less than $5 \mu \mathrm{m}$ ) and zero-valent nano-iron were also evaluated for $\mathrm{Se}$ removal. A series of batch adsorption experiments were conducted to study adsorption kinetics, isotherms, and adsorptive thermodynamics in conjunction with studies on the effects of $\mathrm{pH}$, temperature, concentration, contact time, and presence of competing anions on selenium removal efficiency. 


\subsection{Materials and Methods}

\subsubsection{Materials}

The analytical grade chemicals used were iron (III) sulfate $\left(\mathrm{Fe}_{2}\left(\mathrm{SO}_{4}\right)_{3}\right)$, ammonium hydroxide $\left(\mathrm{NH}_{4} \mathrm{OH}\right)$, sodium hydroxide $(\mathrm{NaOH})$ and sulphuric acid $\left(\mathrm{H}_{2} \mathrm{SO}_{4}\right)$ purchased from Fisher Scientific, Inc.(Rochester, NY). Iron (II) sulfate $\left(\mathrm{FeSO}_{4} \cdot 7 \mathrm{H}_{2} \mathrm{O}\right)$ and sodium selenate $\left(\mathrm{Na}_{2} \mathrm{SeO}_{4}\right)$ were obtained from ACROS Organics (NJ, USA). Sodium selenite $\left(\mathrm{Na}_{2} \mathrm{SeO}_{3}\right)$ was purchased from MP Biomedicals (Solon, $\mathrm{OH}$ ). Natural magnetite ( $<5$ microns, $\left.\mathrm{Fe}_{3} \mathrm{O}_{4}\right)$ was acquired from Cerac Speciality Inorganics and Zerovalent nano-iron was obtained from Quantum Sphere (Santa Ana, CA). All the chemical solutions that were utilized were prepared using Millipore deionized water.

Depending on the redox condition, both selenite and selenate may be present in selenium impaired waters. Therefore, adsorption of both Se species onto magnetite nanoparticles was evaluated although more effort was invested on selenite removal. A stock solution of $100 \mathrm{mg} / \mathrm{L}$ of selenium was prepared with de-ionized water using the aforementioned selenium salts, and the working solutions (50, 100, 250, 500 and 1000 $\mu \mathrm{g}-\mathrm{Se} / \mathrm{L})$ for the adsorption experiments was prepared from the stock solution.

\subsubsection{Adsorbent preparation and characterization}

The synthesis of the nano-magnetite was achieved through coprecipitation at room temperature, in the presence of both ferric and ferrous iron. A solution of

$\left[\mathrm{Fe}^{3+}\right]:\left[\mathrm{Fe}^{2+}\right]=2: 1$ was prepared with deionized water that was deaerated by $\mathrm{N}_{2(\mathrm{~g})}$ bubbling prior to use in order to completely remove dissolved oxygen from the solution. Then, a $25 \%$ ammonium hydroxide solution was gradually added to the solution mixture 
and a black precipitate was observed. Precipitation was allowed to continue at $25^{\circ} \mathrm{C}$ for 30 min, with mechanical stirring and continuous $\mathrm{N}_{2(\mathrm{~g})}$ bubbling. After that, the synthesized nano-magnetite particles were then separated from the solution using an external magnetic field. The black precipitate was then resuspended and washed 3-4 times by adding deionized water followed by centrifiguation using a Sorvall RC 5C plus centrifuge for $10 \mathrm{~min}$ at $4000 \mathrm{rpm}$. Lastly, the nano-magnetite was vacuum-dried and pulverized. The particle size and morphology of synthesized particles were examined by transmission electron microscopy (TEM) using a JEOL 1000 electron microscope (Fig 2.1).The amount of adsorbent applied during each test is reported in grams dry weight. In addition, commercially purchased natural magnetite and zero-valent nano-iron were also evaluated as adsorbents for the purpose of comparison of the effectiveness of synthesized nano-magnetite particles.

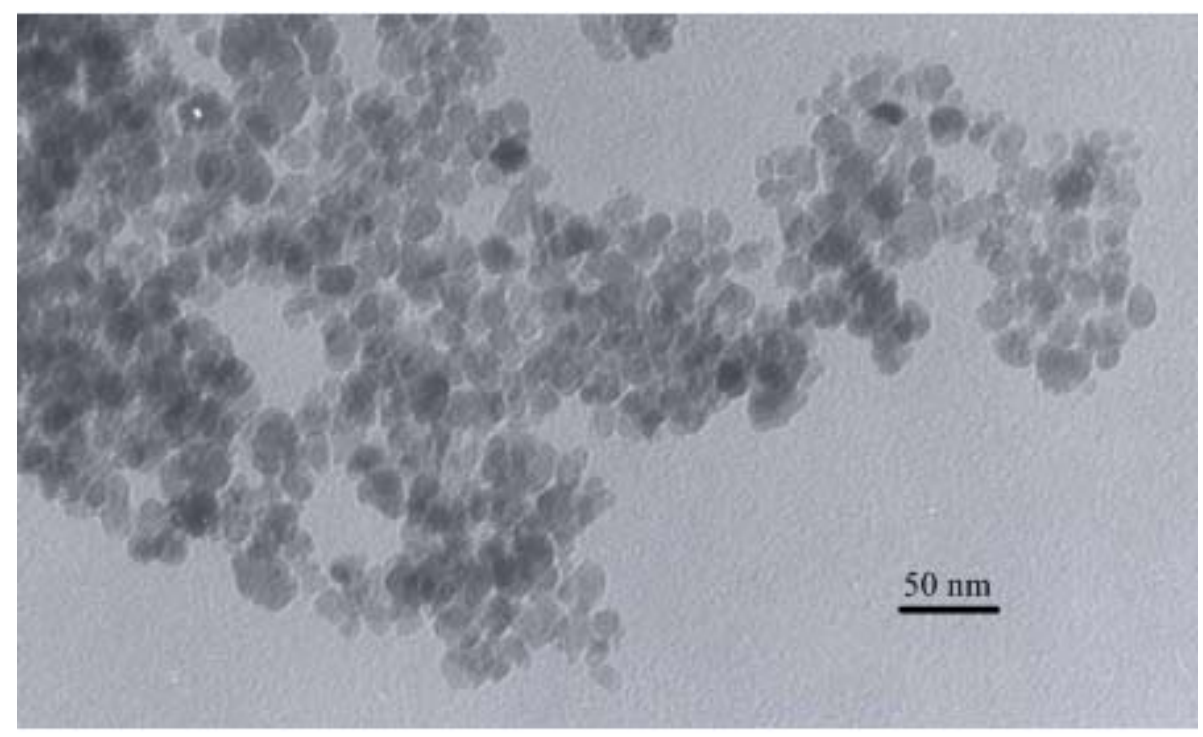

Figure 2.1 TEM micrograph for synthesized nano-magnetite. 


\subsubsection{Batch adsorption studies}

Batch adsorption studies were performed to examine adsorption of selenite onto nano-magnetite by agitating $100 \mathrm{ml}$ of solution containing $\mathrm{Se}$ ions of desired concentration with predetermined amounts of adsorbent using a temperature controlled incubator shaker at $25^{\circ} \mathrm{C}$ for $24 \mathrm{~h}$ at $200 \mathrm{rpm}$. The resulting mixture was separated using an external magnetic field and filtered through a $0.45 \mu \mathrm{m}$ membrane filter and the selenite concentration was measured using a Varian SpectrAA 210 Zeeman graphite furnace atomic absorption spectrometer (GFAAS). All the adsorption tests were carried out in triplicates.

To test the effect of contact time, a series of conical flasks with $100 \mathrm{ml}$ selenite solutions (100 or $250 \mu \mathrm{g} / \mathrm{L}$ in Se) and $0.1 \mathrm{~g} / \mathrm{L}$ nano-magnetite were shaken for periods of time ranging from 5 to $1440 \mathrm{~min}$ at $\mathrm{pH} 4$ and at $25^{\circ} \mathrm{C}$, before samples were taken from the designated flasks and filtered for selenite measurement using GFAAS. The effect of $\mathrm{pH}$ on selenite removal was studied using series of $100 \mathrm{ml}$ solutions at initial Se concentrations 100 and $500 \mu \mathrm{g}-\mathrm{Se} / \mathrm{L}$ with $0.1 \mathrm{~g} / \mathrm{L}$ nano-magnetite at $25^{\circ} \mathrm{C}$. The $\mathrm{pH}$ of the solutions was adjusted between $\mathrm{pH} 2$ to $\mathrm{pH} 9$ with an interval of 1 by adding dilute solutions of $\mathrm{H}_{2} \mathrm{SO}_{4}$ and $\mathrm{NaOH}$ and shaken for $24 \mathrm{hrs}$ to ensure the adsorption equilibrium. To examine the effect of temperatue on selenite adsorption, nano-magnetite was added to batches of $100 \mathrm{~mL}$ selenite solutions (100, 250 and $500 \mu \mathrm{g} / \mathrm{L}$ in Se) to achieve magnetite dose of $0.1 \mathrm{~g} / \mathrm{L}$ and shaken for $24 \mathrm{hrs}$ at a temperature ranging from 25 to $45^{\circ} \mathrm{C}$. For the adsorption isotherm study, $0.01 \mathrm{~g}$ of adsorbent was added to $100 \mathrm{~mL}$ of selenite solution with different concentrations ranging from 50 to $1000 \mu \mathrm{g}-\mathrm{Se} / \mathrm{L}$, and shaken for $24 \mathrm{~h}$ at two different levels of initial $\mathrm{pH}: 4$ and 6 . The performance of nano- 
magnetite on selenium adsorption was compared with, natural magnetite and zero-valent nano-iron. The experiment was carried out with $100 \mathrm{ml}$ solutions of selenite or selenate of $100 \mu \mathrm{g} / \mathrm{L}$ in Se. Different amounts of adsorbents were added to achieve the following doses: $0.1,0.5,1.0,2.0$ and $5.0 \mathrm{~g} / \mathrm{L}$ and the solutions were shaken in a temperature controlled incubator shaker at $25^{\circ} \mathrm{C}$ for $24 \mathrm{~h}$ at $200 \mathrm{rpm}$.

\subsubsection{Effect of Interfering anions}

The effect of competing anions such as chloride, sulfate and nitrate that may coexist with Se oxyanions in water or wastewater was also studied. The experiments were conducted at $25^{\circ} \mathrm{C}$ and $\mathrm{pH} 4.0 \pm 0.1$ and adsorbent dose of $0.1 \mathrm{~g} / \mathrm{L}$ for a contact time of $24 \mathrm{~h}$ with an initial selenite concentration of $250 \mu \mathrm{g}-\mathrm{Se} / \mathrm{L}$. The concentrations of the various anionic species were controlled at $0.05 \mathrm{M}$. In particular, the effect of sulfate anions was further investigated by adjusting its ionic strength at three different levels $(0.01,0.03,0.05$ and $0.1 \mathrm{M})$ with all other conditions remaining unchanged. 


\subsection{Results and discussion}

\subsubsection{Comparison of Nano-magnetite with Natural magnetite and Nano-iron for selenite adsorption}

Presented in Fig. 2.2 is the effect of adsorbent doses on the final selenium concentration for the three adsorbents. With an initial selenite concentration of $100 \mu \mathrm{g}$ $\mathrm{Se} / \mathrm{L}$, the selenium concentration in the effluents decreased with increasing doses for all adsorbents. However, the nano-magnetite synthesized for this study clearly had superior adsorption performance in removal capacity as opposed to natural magnetite and nanoiron, as demonstrated in Fig. 2.2. For nano-mangetite, much of the rapid decrease of Se concentration was observed to have occurred at a dose of $0.1 \mathrm{~g} / \mathrm{L}$, where the $\mathrm{Se}$ concentration was $\sim 3 \mu \mathrm{g}-\mathrm{Se} / \mathrm{L}$ and nano-magnetite adsorption capacity was $\sim 1 \mathrm{mg}-\mathrm{Se} / \mathrm{g}$ adsorbent. For the natural magnetite at a dose of $0.1 \mathrm{~g} / \mathrm{L}$, the adsorption capacity and final selenite concentration was $0.3 \mathrm{mg}$-Se/g-adsorbent and $76.6 \mu \mathrm{g}-\mathrm{Se} / \mathrm{L}$ respectively. When nano-iron was used at the same dose, the adsorption capacity and final selenite concentration was $0.8 \mathrm{mg}-\mathrm{Se} / \mathrm{g}$-adsorbent and $20 \mu \mathrm{g}-\mathrm{Se} / \mathrm{L}$ respectively. The greater surface area offered by the nano-magnetite due to its size in comparison to the natural magnetite $(5 \mu \mathrm{m})$ might be the reason for better selenite adsorption. The poor performance of nano-iron could be due to the surface oxidation of iron to iron oxides and severe agglomeration. 


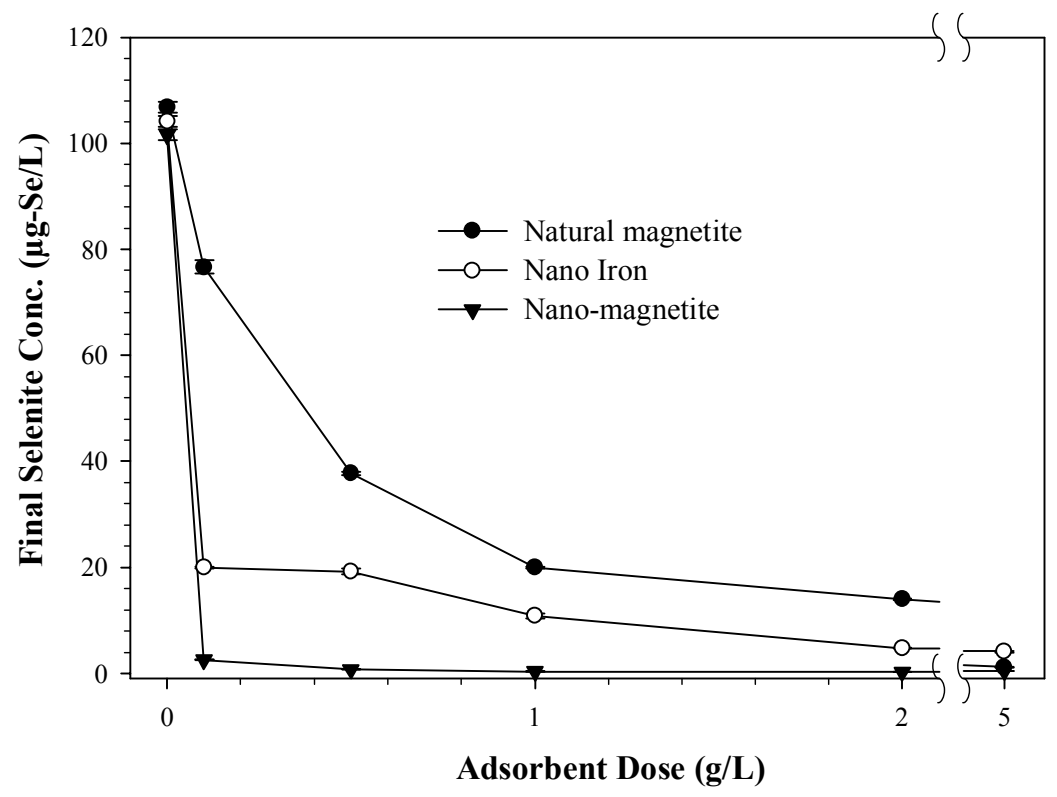

Figure 2.2 Effect of selenite removal by three different materials at varying dosages (mixing time $24 \mathrm{~h} ; 25^{\circ} \mathrm{C} ; \mathrm{pH} 4.0 \pm 0.1$; initial concentration $100 \mu \mathrm{g}-\mathrm{Se} / \mathrm{L}$ ).

\subsubsection{Comparison of Nano-magnetite with Natural magnetite and Nano-iron for selenate adsorption}

Further study was conducted to investigate if the nano-magnetite was equally efficient in removing selenate from water/wastewater since most oxidized mine influenced waters contain selenium as selenate oxyanions. The effect of adsorbent doses on the final selenium concentration for the three adsorbents is presented in Fig. 2.3. Clearly, natural magnetite was ineffective in removing selenate from aqueous solutions. Compared with Fig. 2.2, nano-iron demonstrated similar adsorption performance for both selenite and selenate, while nano-magnetite showed lower adsorption for selenate than selenite. The lower adsorption of magnetite for selenate is not in agreement with a previous study by Martinez et al. (2006), who found that magnetite had similar or greater 
adsorption for selenate as compared to selenite. The better adsorption of nano-iron for selenate as opposed to nano-magnetite might be contributed to its stronger reducing power which can convert selenate to selenite, which is generally considered an easier target for adsorption.

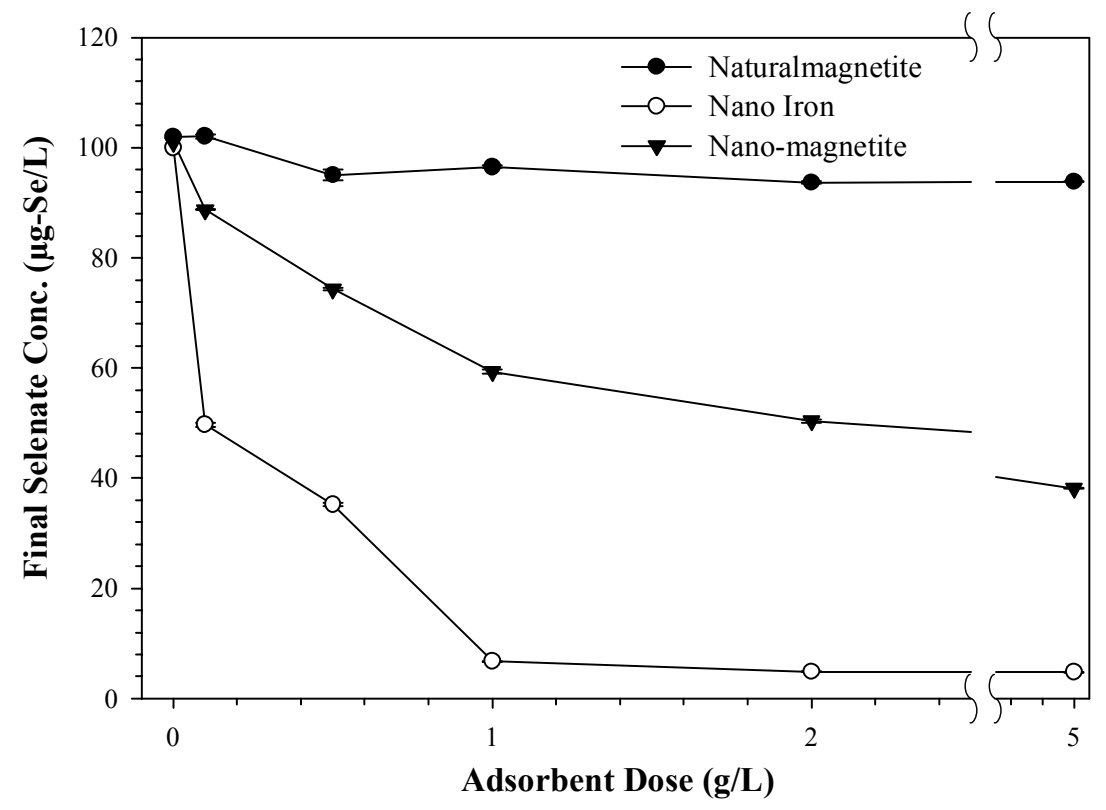

Figure 2.3 Effect of selenate removal by three different materials at varying dosages (mixing time $24 \mathrm{~h} ; 25^{\circ} \mathrm{C} ; \mathrm{pH} 4.0 \pm 0.1$; initial concentration $100 \mu \mathrm{g}-\mathrm{Se} / \mathrm{L}$ ).

\subsubsection{Effect of contact time}

The effect of contact time on final selenite concentration for initial Se concentrations of $100 \mu \mathrm{g} / \mathrm{L}$ and $200 \mu \mathrm{g} / \mathrm{L}$ is presented in Fig. 2.4. Rapid adsorption was observed in the first $30 \mathrm{~min}$ with almost $50 \%$ removal of selenite, thereafter the adsorption slowed down and gradually reached equilibrium. Consequently, $24 \mathrm{~h}$ mixing was used as the contact time in all further adsorption tests since no significant adsorption was observed after that time period. A similar behavior was observed for selenium 
adsorption on a tropical soil in which the adsorption rate was reported to have been rapid in the first hour, plateaued after $8 \mathrm{~h}$ and approached equilibrium at about $24 \mathrm{~h}$ (Goh and Lim, 2004). A few other studies in the literature using iron oxide as adsorbents reported comparatively shorter time required for adsorption, such as 1 min required for chitosanbound $\mathrm{Fe}_{3} \mathrm{O}_{4}$ nanoprticles as a magnetic nano-adsorbent for the removal of $\mathrm{Cu}$ (II) ions (Chang et al., 2004), or $2 \mathrm{~h}$ reported for adsorption of selenite on different forms of iron oxyhydroxides and ferihydrite (Parida et al., 1997) or $3 \mathrm{~h}$ for removal of fluoride and phosphate from wastewater using nano-magnetite aggregated iron oxide hydroxide (Eskandarpour et al., 2006).

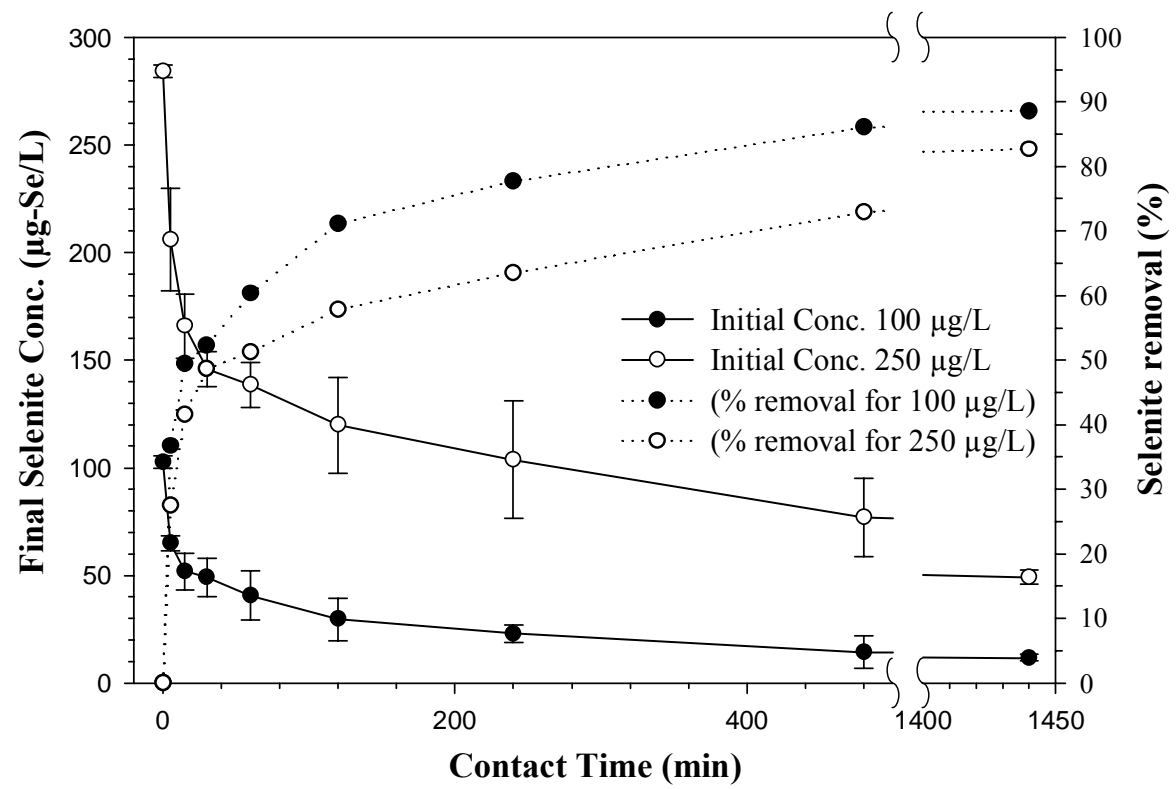

Figure 2.4 Effect of contact time on final selenite concentration (adsorbent dose 0.1 $\mathrm{g} / \mathrm{L} ; \mathrm{pH} 4.0 \pm 0.1 ; 25^{\circ} \mathrm{C} ; 24 \mathrm{~h}$ mixing time; initial concentrations $100 \mu \mathrm{g}-\mathrm{Se} / \mathrm{L}$ and $250 \mu \mathrm{g}-\mathrm{Se} / \mathrm{L})$. 


\subsubsection{Effect of pH}

The effect of $\mathrm{pH}$ on adsorption is an important consideration in adsorption studies. The effect of $\mathrm{pH}$ on final selenite concentration is shown in Fig 2.5. The sorption of selenite decreased as $\mathrm{pH}$ increased from 4.0 to 9.0 , indicating that lower $\mathrm{pH}$ favored selenium adsorption. When $\mathrm{pH}$ was lower than 4.0, the selenite adsorption onto nanomagnetite was relatively independent of $\mathrm{pH}$. The trend follows similar behavior irrespective of initial concentrations of $100 \mu \mathrm{g}-\mathrm{Se} / \mathrm{L}$ and $500 \mu \mathrm{g}-\mathrm{Se} / \mathrm{L}$ showing a significant decrease in selenite adsorption at $\mathrm{pH} \geq 8.0$. This behavior can be attributed to two theories, namely surface charge and speciation of selenium in aqueous solution. Maximum sorption is observed when surface charge of nano-magnetite is positive in accordance with the point of zero charge (PZC) of iron oxide that indicates surface charge is positive below $\mathrm{pH} 8.0$ and negative above pH 9.0 (Cornell and Schwertmann, 2003). The greater adsorption achieved at $\mathrm{pH}<8.0$ is due to the attraction between anionic selenite ions and positively charged adsorbent surfaces and vice versa at $\mathrm{pH}>$ 9.0. In addition, the biselenite $\left(\mathrm{HSeO}_{3}{ }^{-}\right)$ion being the predominant ion in aqueous solution at a $\mathrm{pH}$ range between 3.5 and 8.0 is responsible for maximum adsorption at the low $\mathrm{pH}$, whereas above $\mathrm{pH} 8.0$ selenite $\left(\mathrm{SeO}_{3}{ }^{2-}\right)$ species dominates and still occurs in solution (Linkson, 1990; El-Shafey, 2007; Rovira et al., 2008). Similar trends have been previously observed in case of selenite adsorption onto iron oxyhydroxides and ferihydrite and were attributed to characteristic anionic behavior of selenite species (Parida et al., 1997). The similarity repeats with selenite adsorption studies using goethite and hematite where the sorption edge for selenite is reported to coincide with the 
predominance of $\mathrm{HSeO}_{3}{ }^{-}$(Rovira et al., 2008) and in case of magnetite where $\mathrm{HSeO}_{3}{ }^{-}$ predominance is mentioned (Martinez et al., 2006).

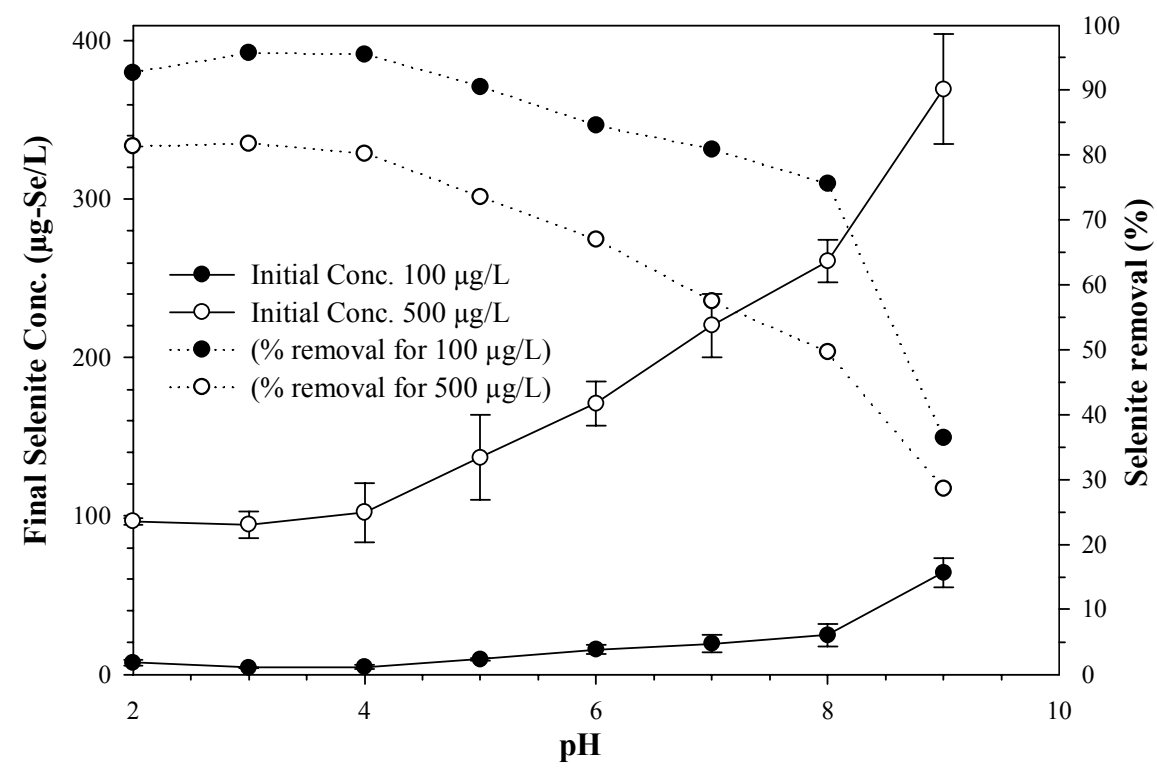

Figure 2.5 Effect of $\mathrm{pH}$ on final selenite concentration (adsorbent dose $0.1 \mathrm{~g} / \mathrm{L}$; pH $4.0 \pm 0.1$; mixing time $24 \mathrm{~h} ; 20^{\circ} \mathrm{C}$; initial concentration $100 \mu \mathrm{g} / \mathrm{L}$ and $\left.500 \mu \mathrm{g}-\mathrm{Se} / \mathrm{L}\right)$.

\subsubsection{Effect of temperature and Adsorption Thermodynamics}

The effect of temperature on final selenite concentration is presented in Fig.2.6. It was observed that the final selenite concentration decreased as temperature increased from $25^{\circ} \mathrm{C}$ to $45^{\circ} \mathrm{C}$, at which point, the removal efficiency for selenite was above $90 \%$. The trend was independent of the initial selenium concentrations, indicating high temperatures favor selenite adsorption onto the surfaces of nano-magnetite. The results are in agreement with previous studies, in which selenite removal was achieved using iron-coated granular activated carbon (GAC) and the selenite concentration decreased as temperature increased from $25^{\circ} \mathrm{C}$ to $45^{\circ} \mathrm{C}$ (Zhang et al., 2008). Selenite adsorption onto 
untreated $\mathrm{Fe}(\mathrm{III}) / \mathrm{Cr}(\mathrm{III})$ hydroxide solid waste increased between 32 to $60{ }^{\circ} \mathrm{C}$ (Navasivayam and Prathap, 2006). The same follows with selenite adsorption using manganese nodule leached residues between 25 to $55{ }^{\circ} \mathrm{C}$ (Dash and Parida, 2006) and increased selenite sorption onto sulphuric acid-treated peanut shell between $25^{\circ} \mathrm{C}$ to $45^{\circ} \mathrm{C}$ (Shafey, 2007).

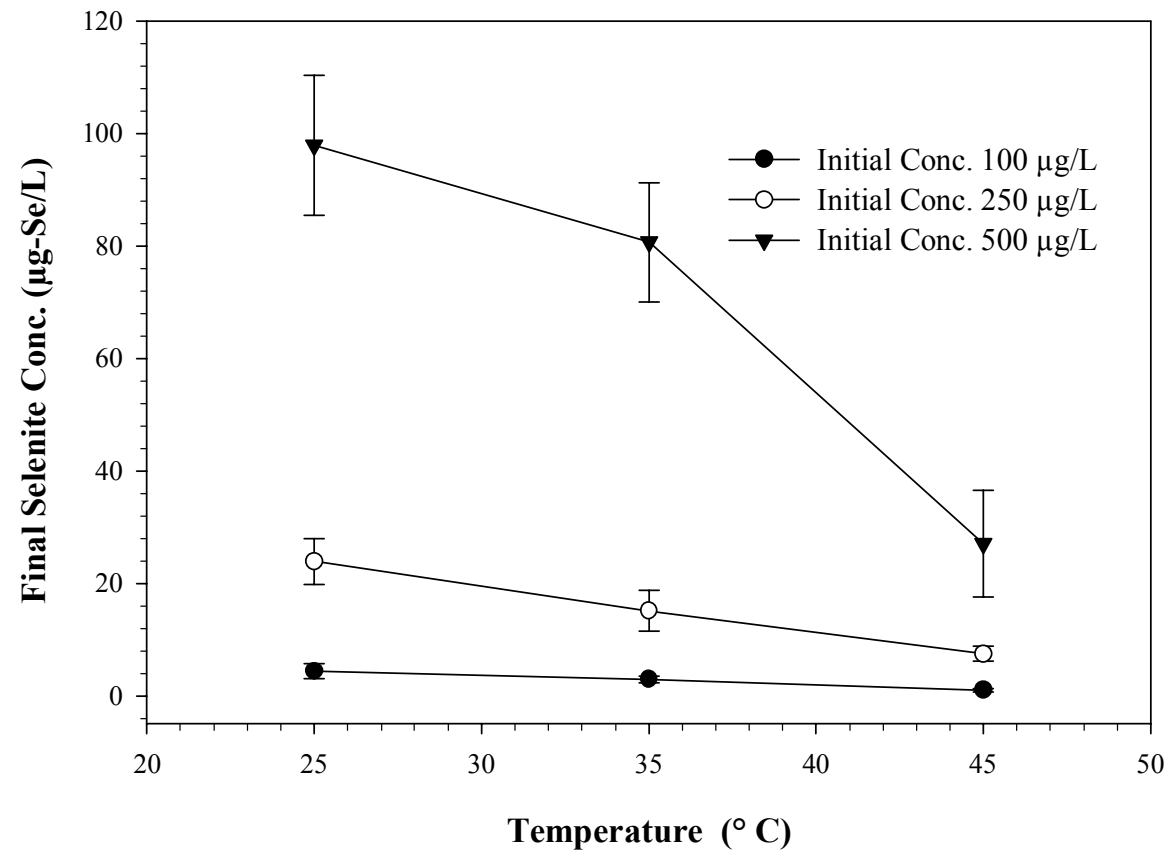

Figure 2.6 Effect of temperature on final selenite concentration (adsorbent dose 0.1 $\mathrm{g} / \mathrm{L} ; \mathrm{pH} 4.0 \pm 0.1$; mixing time $24 \mathrm{~h}$; initial concentrations 100,250 and $500 \mu \mathrm{g}$ $\mathrm{Se} / \mathrm{L})$.

The thermodynamic parameters free energy $\left(\Delta G^{o}\right)$, enthalpy $\left(\Delta H^{o} a d s\right)$, and entropy $\left(\Delta S^{\circ}\right)$ of adsorption were calculated in order to explain the thermodynamic nature involved in the adsorption process. Free energy change $\left(\Delta G^{\circ}\right)$ was calculated from the relation:

$$
\Delta G^{o}=-R T \ln K_{c}
$$


where $R=$ gas constant $(8.314 \mathrm{~kJ} / \mathrm{kmol} / \mathrm{K}) ; T=$ absolute temperature in Kelvin and $K_{c}=$ equilibrium constant (ratio of the concentration of selenite ions adsorbed on nanomagnetite to that of selenite ions in the aqueous phase at equilibrium). The Van't Hoff equation given below yields the values of enthalpy $\left(\Delta H^{o}{ }_{a d s}\right)$, and entropy $\left(\Delta S^{\circ}\right)$ estimated from the slope and intercept of the linear plots of $\ln \left(K_{c}\right)$ vs. 1/T (Fig.2.7)

$$
\ln \left(K_{c}\right)=\frac{-\Delta H_{a d s}^{0}}{R T}+\frac{\Delta S^{0}}{R}
$$

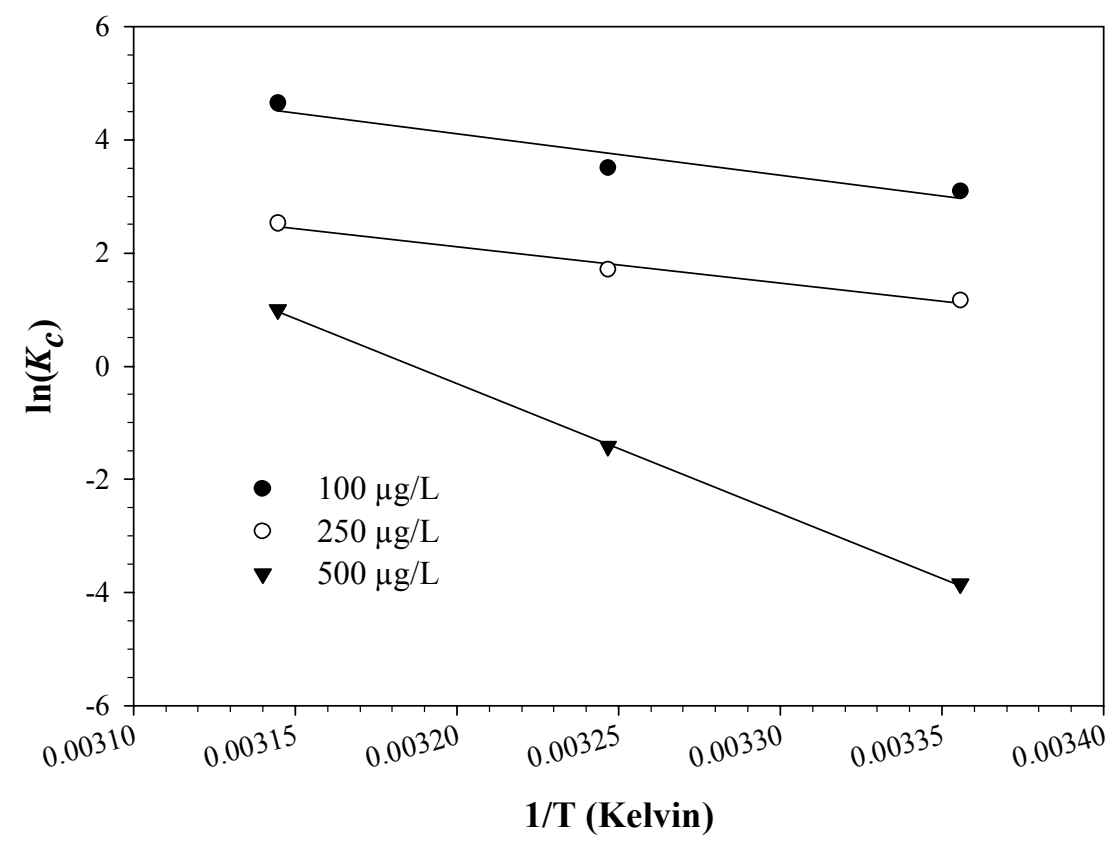

Figure 2.7 Van't Hoff plot for selenite concentration (adsorbent dose $0.1 \mathrm{~g} / \mathrm{L} ; \mathrm{pH} 4.0$ \pm 0.1 ; mixing time $24 \mathrm{~h}$; initial concentrations 100,250 and $500 \mu \mathrm{g}-\mathrm{Se} / \mathrm{L}$ ).

The calculated thermodynamic parameters are presented in the Table 2.1. The negative values of $\Delta G^{o}$ indicated the spontaneity of the adsorption process. The positive value of $\Delta H^{o}$ ads indicated endothermic adsorption, which explains why the temperature increase resulted in enhanced selenite adsorption onto the surfaces of nano-magnetite 
(Fig. 2.6). Higher temperature might also have increased the kinetic energy of selenite ions so that they could transport easily to adsorption sites. The finding was consistent with selenite adsorption onto untreated $\mathrm{Fe}(\mathrm{III}) / \mathrm{Cr}(\mathrm{III})$ hydroxide solid waste and manganese nodule leached residues (Navasivayam and Prathap, 2006; Dash and Parida, 2006) respectively. The positive value of entropy change $\left(\Delta S^{0}\right)$ reveals an increase in randomness at the solid/solution interface during the adsorption of selenite onto nanomagnetite.

Table 2.1 Thermodynamic parameters for the adsorption of selenite on nanomagnetite at different temperatures.

\begin{tabular}{|c|c|c|c|c|c|}
\hline $\begin{array}{c}\text { Initial } \\
\text { selenite conc. } \\
(\mu \mathrm{g}-\mathrm{Se} / \mathrm{L})\end{array}$ & $\begin{array}{c}\text { Temperature } \\
\left({ }^{\circ} \mathrm{C}\right)\end{array}$ & $\mathrm{K}_{\mathrm{c}}$ & $\begin{array}{c}\Delta \mathrm{G}^{0} \\
(\mathrm{~kJ} / \mathrm{mol})\end{array}$ & $\begin{array}{c}\Delta \mathrm{H}^{0} \text { ads } \\
(\mathrm{kJ} / \mathrm{mol})\end{array}$ & $\begin{array}{c}\Delta S^{0} \\
(\mathrm{~kJ} / \mathrm{mol} / \mathrm{K})\end{array}$ \\
\hline \multirow{3}{*}{100} & 25 & 22.9 & -7.7 & \multirow{3}{*}{7.32} & \multirow{3}{*}{0.028} \\
\hline & 35 & 33.3 & -9.0 & & \\
\hline & 45 & 103.5 & -12.2 & & \\
\hline \multirow{3}{*}{250} & 25 & 3.2 & -2.9 & \multirow{3}{*}{6.43} & \multirow{3}{*}{0.023} \\
\hline & 35 & 5.5 & -4.4 & & \\
\hline & 45 & 12.5 & -6.7 & & \\
\hline \multirow{3}{*}{500} & 25 & 0.02 & 9.5 & \multirow{3}{*}{22.9} & \multirow{3}{*}{0.073} \\
\hline & 35 & 0.2 & 3.7 & & \\
\hline & 45 & 2.7 & -2.6 & & \\
\hline
\end{tabular}

\subsubsection{Adsorption isotherms}

Adsorption isotherm equations predict adsorption processes at equilibrium conditions and thereby are the best means of assessing the performance of a system (Shaik and Bhavanath, 2008). Among the various isotherm models available, twoparameter models such as Langmuir, Freundlich and Elovich models were applied to characterize selenite adsorption. 
The adsorption of selenite by nano-magnetite was well applied to the Freundlich isotherm that is expressed by the equation given below:

$$
q_{e}=K C_{e}^{1 / n}
$$

where $C_{e}$ and $q_{e}$ are equilibrium selenite concentration in solution $(\mu \mathrm{g} / \mathrm{L})$ and the corresponding adsorption capacity on nano-magnetite ( $\mu$ g-Se/g-adsorbent), and $K$ and $1 / n$ are empirical constants determined through regression analysis. The relationship between final selenite concentration and adsorption capacity of nano-magnetite is illustrated in the Fig.2.8, indicating a good applicability of Freundlich isothems. The parameters of the Freundlich isotherm model are listed in Table 2.2. The adsorption capacity at $\mathrm{pH} 4.0$ was approximately $470 \mu \mathrm{g}$-Se/g-nano-magnetite with a final selenite concentration of 0.80 $\mu \mathrm{g}-\mathrm{Se} / \mathrm{L}$ and increased to $7500 \mu \mathrm{g}$-Se/g-nano-magnetite with a final selenite concentration of $347 \mu \mathrm{g}-\mathrm{Se} / \mathrm{L}$. The adsorption capacity was similar at $\mathrm{pH} 6.0$ with 400 $\mu \mathrm{g}$-Se/g-nano-magnetite at $3.11 \mu \mathrm{g}-\mathrm{Se} / \mathrm{L}$ and $7000 \mu \mathrm{g}$-Se/g-nano-magnetite at $370 \mu \mathrm{g}$ Se/L. As depicted in Fig. 2.8, a linear relationship $\left(\mathrm{r}^{2}=0.9973\right)$ exists between $q_{e}$ and $\mathrm{C}_{\mathrm{e}}$ at $\mathrm{pH} 4.0$ when plotted on a log-log scale. A similar linear relationship $\left(\mathrm{r}^{2}=0.9966\right)$ at $\mathrm{pH}$ 6.0. The values of $n$ of the Freundlich model fell in the range of 1 to 10 indicating favorable adsorption (Basha and Jha, 2008). The $n$ values of $2.19(\mathrm{pH} 4.0)$ and $1.80(\mathrm{pH}$ 6.0) (Table 2.2) represented good and moderately difficult adsorption characteristics respectively (Hamdaoui and Naffrechoux, 2007). In addition, the applicability of the Freundilch isotherm model revealed that selenite adsorption took place heterogeneously due to the diversity of sorption sites offered by the nano-magnetite. 


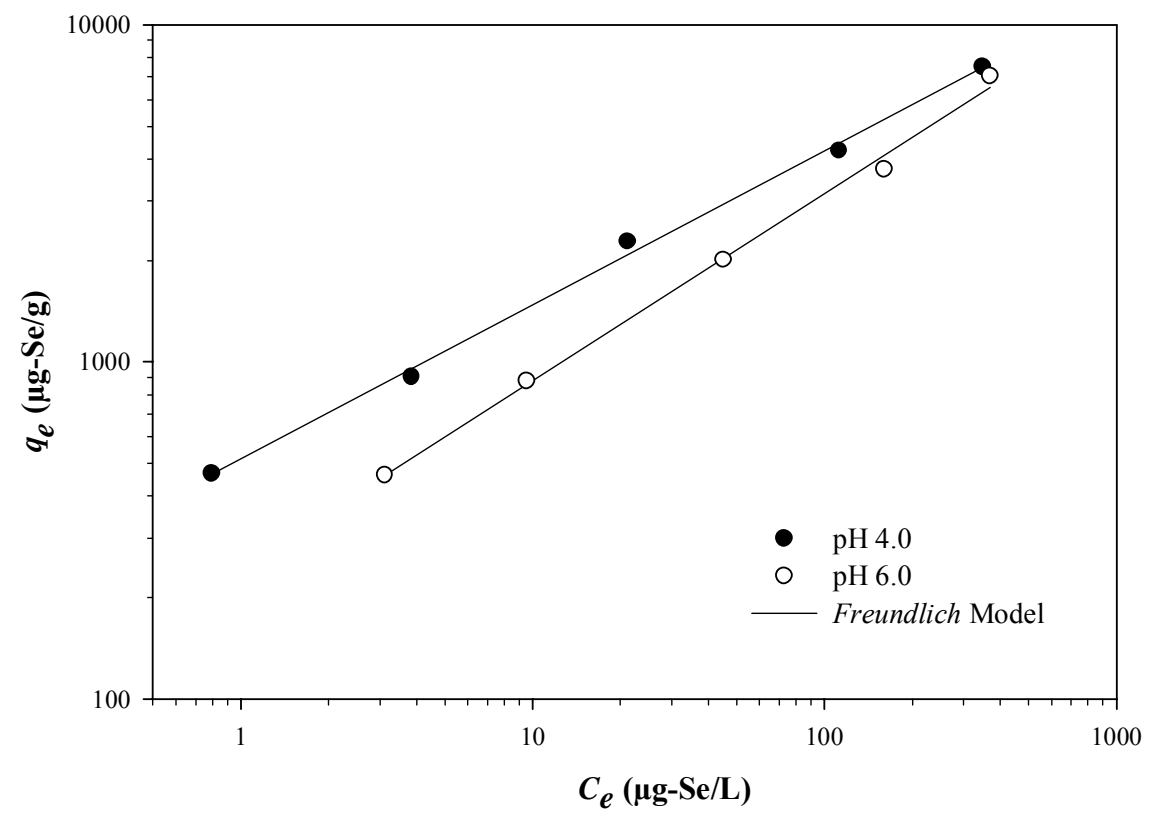

Figure 2.8 Freundlich isotherm of selenite adsorption by nano-magnetite (adsorbent dose $0.1 \mathrm{~g} / \mathrm{L}$; mixing time $24 \mathrm{~h} ; 25^{\circ} \mathrm{C}$ ).

A non-linear form of the Langmuir isotherm is as given below:

$$
q_{e}=\frac{q_{m} b C_{e}}{1+b C_{e}}
$$

where $\mathrm{C}_{\mathrm{e}}$ and $q_{e}=$ equilibrium selenite concentration in solution $(\mu \mathrm{g} / \mathrm{L})$ and the corresponding adsorption capacity on nano-magnetite ( $\mu \mathrm{g}-\mathrm{Se} / \mathrm{g}$-adsorbent) respectively; $q_{m}$ and $b=$ Langmuir constants; $q_{m}=$ maximum adsorption capacity ( $\mu$ g-Se/g-adsorbent) based on monolayer surface coverage and $b=$ constant $(\mathrm{L} / \mu \mathrm{g})$ associated with energy of adsorption as determined from the slope and intercept of the regression line for different initial selenium concentrations. The parameters of the Langmuir isotherm model are listed in Table 2.2. The Langmuir isotherm model yielded similar values of $q_{m}=10,000$ $\mu \mathrm{g}-\mathrm{Se} / \mathrm{g}$-nano-magnetite at both $\mathrm{pH} 4.0$ as well as $\mathrm{pH} 6.0$ but a larger value of parameter 
$b$ at $\mathrm{pH} 4.0$ suggests higher affinity of selenite ions to nano-magnetite when compared to that at $\mathrm{pH}$ 6.0. Further, lower regression coefficients $\left(\mathrm{r}^{2}=0.9475\right)$ at $\mathrm{pH} 4.0$ as well as at pH 6.0 for which $\left(r^{2}=0.8662\right)$ when compared to the Freundlich model indicate that the Freundlich isotherm was more suitable for the experimental data than was the Langmuir isotherm in both cases (Fig. 2.9). Unlike the various studies found in the literature pertaining to use of iron based technologies or sorption studies with selenite and selenate that conform well with the Langmuir isotherm model (Martinez et al., 2006; Rovira et al., 2007; Zhang et al., 2008; Dash et al., 2006; Namasivayam and Pratap, 2006 ), the Freundlich model resulted in a better fit than the Langmuir isotherm model for adsorption of both $\mathrm{Se}(\mathrm{IV})$ and $\mathrm{Se}(\mathrm{VI})$ species in surface coal mine environment soils (Sharmasarkar et al, 2001) as it did with this study. However, in spite of significant differences in adsorbent characteristics and experimental procedures between the present study and those that aimed at selenite adsorption, the $q_{m}$ value, $10.0 \mathrm{mg}$-Se/g-nano-magnetite was much higher than the value $2.58 \mathrm{mg}$-Se/g-iron coated GAC for selenite removal (Zhang et al., 2008). The value of $b, 17.86 \mathrm{~L} / \mathrm{mg}$ was comparable with the value $18.4 \mathrm{~L} / \mathrm{mg}$ of the iron coated GAC. The value of $q_{m}=10.0 \mathrm{mg}$-Se/g-nano-magnetite was comparable to the value $9.3 \mathrm{mg} / \mathrm{g}$ for water-washed manganese nodule leached residue for selenite removal (Dash and Parida, 2006) and lower than $15.63 \mathrm{mg} / \mathrm{g}$ for pre-treated $\mathrm{Fe}(\mathrm{III}) / \mathrm{Cr}$ (III) hydroxide adsorbent (Namasivayam and Pratap, 2006). 


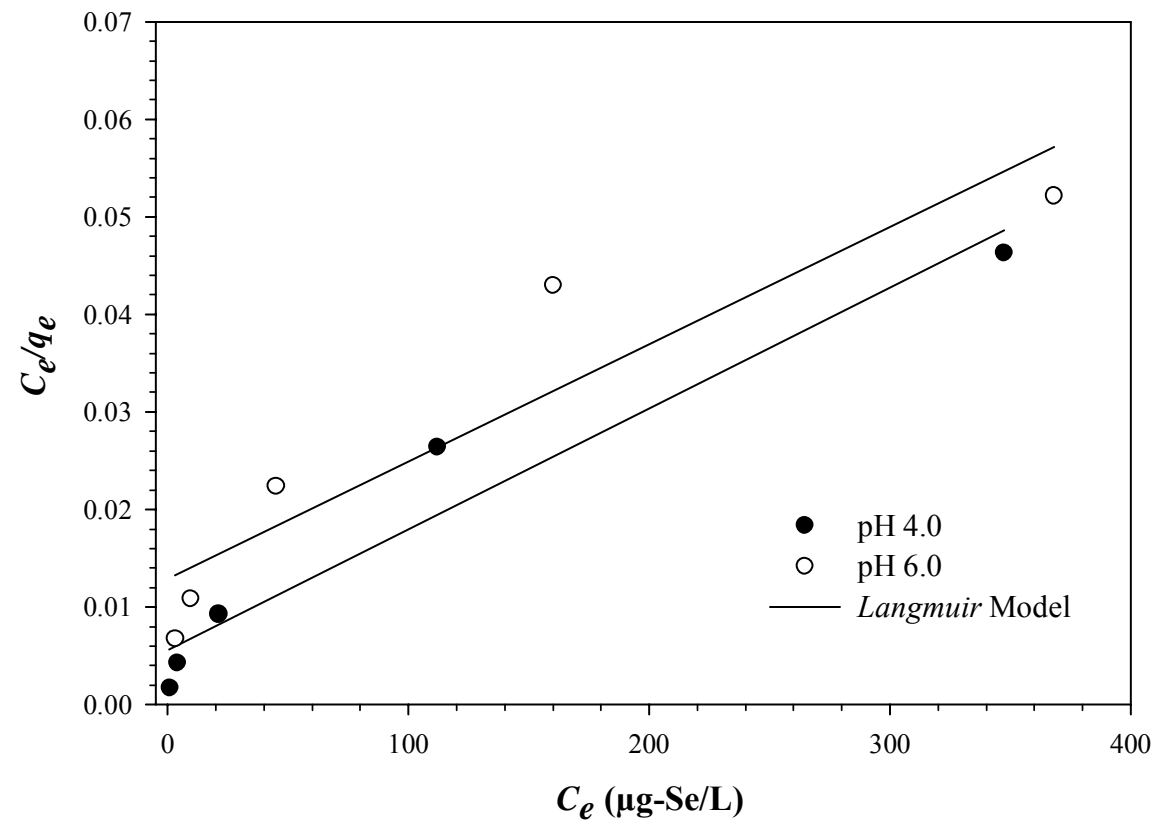

Figure 2.9 Langmuir isotherm of selenite adsorption by nano-magnetite (adsorbent dose $0.1 \mathrm{~g} / \mathrm{L}$; mixing time $24 \mathrm{~h} ; 25^{\circ} \mathrm{C}$ ).

The Elovich model is expressed by the relation: (Hamdaoui and Naffrechoux, 2007).

$$
\frac{q_{e}}{q_{m}}=K_{E} C_{e} \exp \left(-\frac{q_{e}}{q_{m}}\right)
$$

where $K_{\mathrm{E}}$ is the Elovich equilibrium constant $(\mathrm{L} / \mu \mathrm{g})$ and $q_{m}$ is the Elovich maximum adsorption capacity ( $\mu \mathrm{g}-\mathrm{Se} / \mathrm{g}$-adsorbent) based on the assumption that the adsorption sites increase exponentially with adsorption, implying a multilayer adsorption. If the adsorption follows the Elovich equation, then the Elovich maximum adsorption capacity and Elovich constant can be calculated from the slopes and the intercepts of the plot ln $\left(q_{e} / \mathrm{C}_{\mathrm{e}}\right)$ versus $q_{e}$. The parameters of the Elovich isotherm model are listed in Table 2.2. The data from the experiments exhibited lower values of coefficient of correlation than 
both the Freundlich and Langmuir isotherm models implying that multilayer adsorption due to exponential covering of adsorption sites does not exist in the studied concentration range in case of nano-magnetite (Fig.2.10).

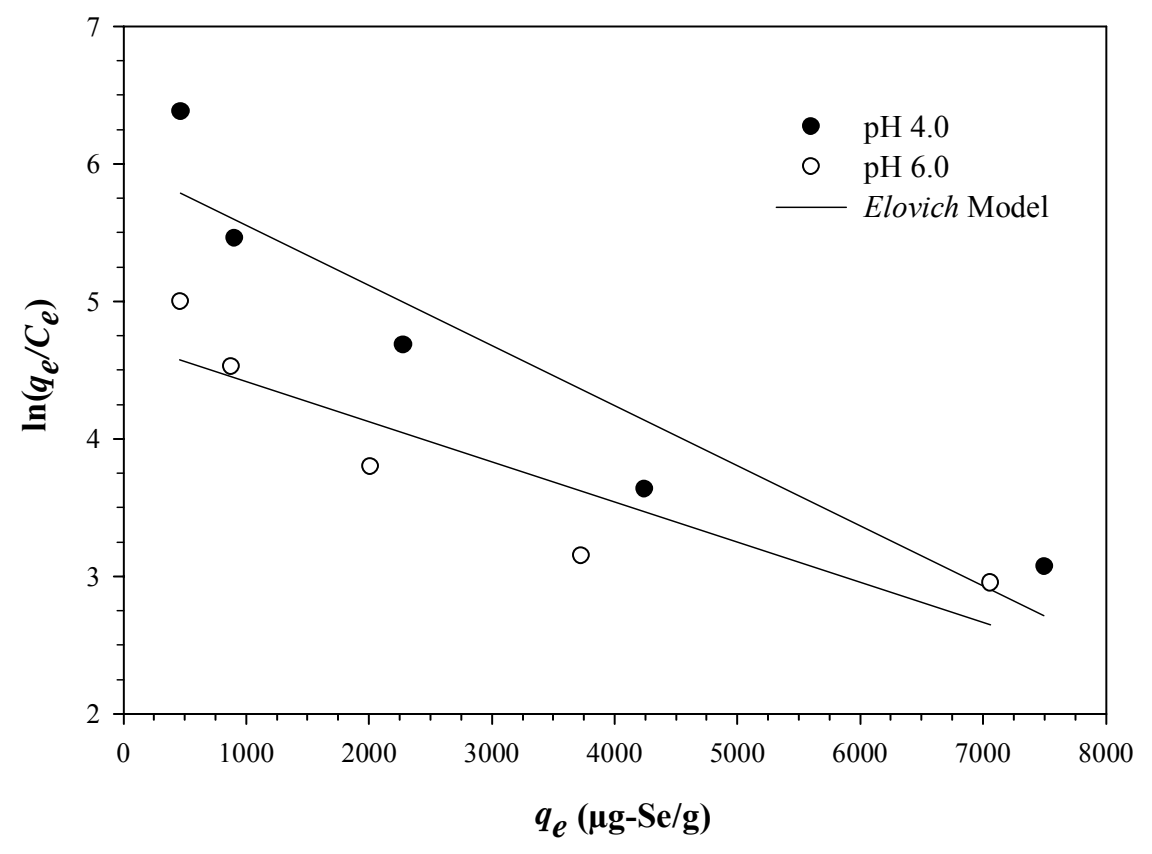

Figure 2.10 Elovich isotherm of selenite adsorption by nano-magnetite (adsorbent dose $0.1 \mathrm{~g} / \mathrm{L}$; mixing time $24 \mathrm{~h} ; 25^{\circ} \mathrm{C}$ ).

Table 2.2 Freundlich, Langmuir and Elovich parameters for the adsorption of selenite on nano-magnetite.

\begin{tabular}{|c|c|c|c|c|c|c|}
\hline $\mathrm{pH}$ & \multicolumn{2}{|c|}{ Freundlich } & \multicolumn{2}{|c|}{ Langmuir Constants } & \multicolumn{2}{|c|}{ Elovich Constants } \\
\hline & $K(\mu \mathrm{g} / \mathrm{g})$ & 516.1 & $b(\mathrm{~L} / \mu \mathrm{g})$ & 0.018 & $K_{E}(\mathrm{~L} / \mu \mathrm{g})$ & 6.0 \\
\hline 4.0 & $\begin{array}{l}n \\
\mathrm{r}^{2}\end{array}$ & $\begin{array}{c}2.2 \\
0.9973\end{array}$ & $\begin{array}{c}q_{m}(\mu \mathrm{g} / \mathrm{g}) \\
\mathrm{r}^{2}\end{array}$ & $\begin{array}{c}10000.0 \\
0.9475\end{array}$ & $\begin{array}{c}q_{m}(\mu \mathrm{g} / \mathrm{g}) \\
\mathrm{r}^{2}\end{array}$ & $\begin{array}{l}2500.0 \\
0.8818\end{array}$ \\
\hline 6.0 & $\begin{array}{c}K(\mu \mathrm{g} / \mathrm{g}) \\
n \\
\mathrm{r}^{2}\end{array}$ & $\begin{array}{c}245.5 \\
1.8 \\
0.8662\end{array}$ & $\begin{array}{c}b(\mathrm{~L} / \mu \mathrm{g}) \\
q_{m}(\mu \mathrm{g} / \mathrm{g}) \\
\mathrm{r}^{2}\end{array}$ & $\begin{array}{c}0.008 \\
10000.0 \\
0.9966 \\
\end{array}$ & $\begin{array}{c}K_{E}(\mathrm{~L} / \mu \mathrm{g}) \\
q_{m}(\mu \mathrm{g} / \mathrm{g}) \\
\mathrm{r}^{2}\end{array}$ & $\begin{array}{c}4.7 \\
3333.3 \\
0.8020\end{array}$ \\
\hline
\end{tabular}




\subsubsection{Adsorption Kinetics}

In order to understand the adsorption kinetics, two different kinetic models were studied. The pseudo-first-order kinetic model expressed by the Lagregren equation, (Eq. (6)):

$$
\log \left(q_{e}-q_{t}\right)=\log q_{e}-\frac{K_{1}}{2.303} \times t
$$

where $q_{e}$ and $q_{t}$ are the amount of selenite sorbed( $\mu \mathrm{g}$-Se/g-adsorbent) at equilibrium and at time $t$, respectively and $K_{l}$ is the pseudo-first-order equilibrium rate constant $\left(\mathrm{min}^{-1}\right)$. A plot of $\log \left(q_{e}-q_{t}\right)$ vs. $t$ gives straight line indicating the applicability of the pseudo-firstorder rate equation (Fig. 11).

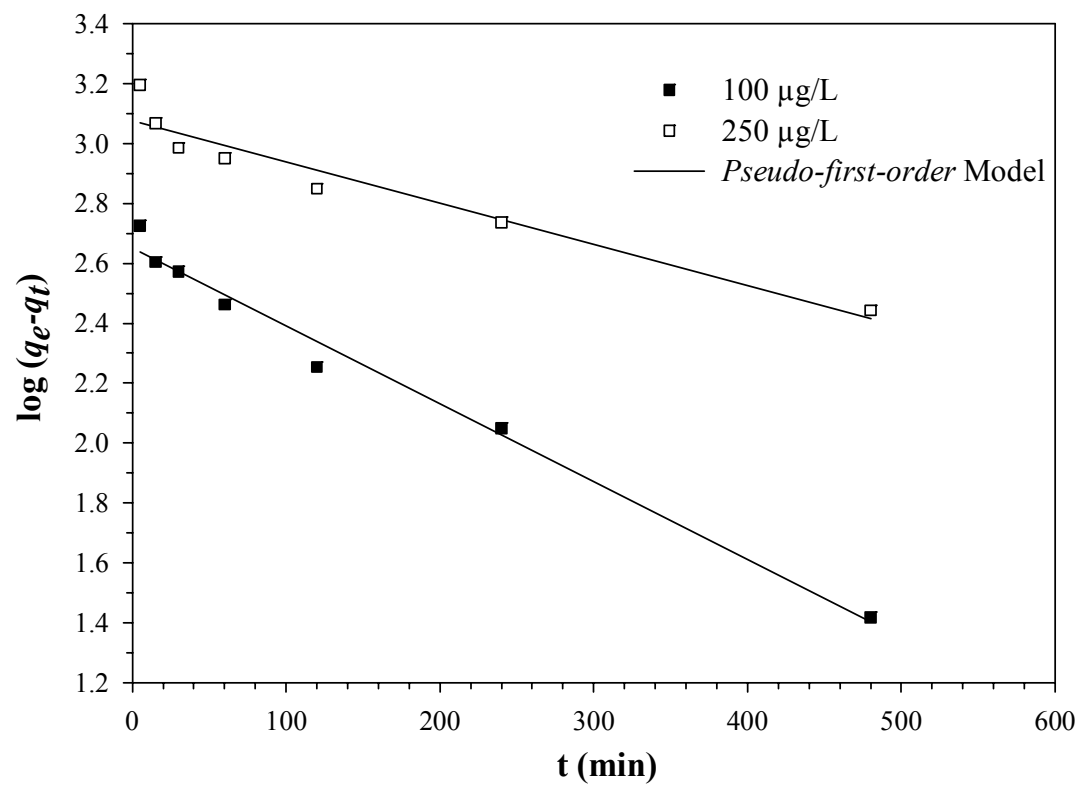

Figure 2.11 Pseudo-first-order kinetics for sorption of selenite by nano-magnetite (adsorbent dose $0.1 \mathrm{~g} / \mathrm{L}$; pH 4.0 \pm 0.1 ; mixing time $24 \mathrm{~h} ; 25^{\circ} \mathrm{C}$ ). 
The pseudo-second-order sorption rate equation may be expressed as:

$$
\frac{t}{q_{t}}=\frac{1}{K_{2} q_{e}}+\frac{1}{q_{e}} \times t
$$

$K_{2}$ is the pseudo-second-order sorption rate constant $(\mathrm{g} / \mu \mathrm{g} / \mathrm{min})$. Straight line plot of $t / q_{t}$ vs. $t$ indicates the applicability of pseudo-second-order model (Fig. 2.12).

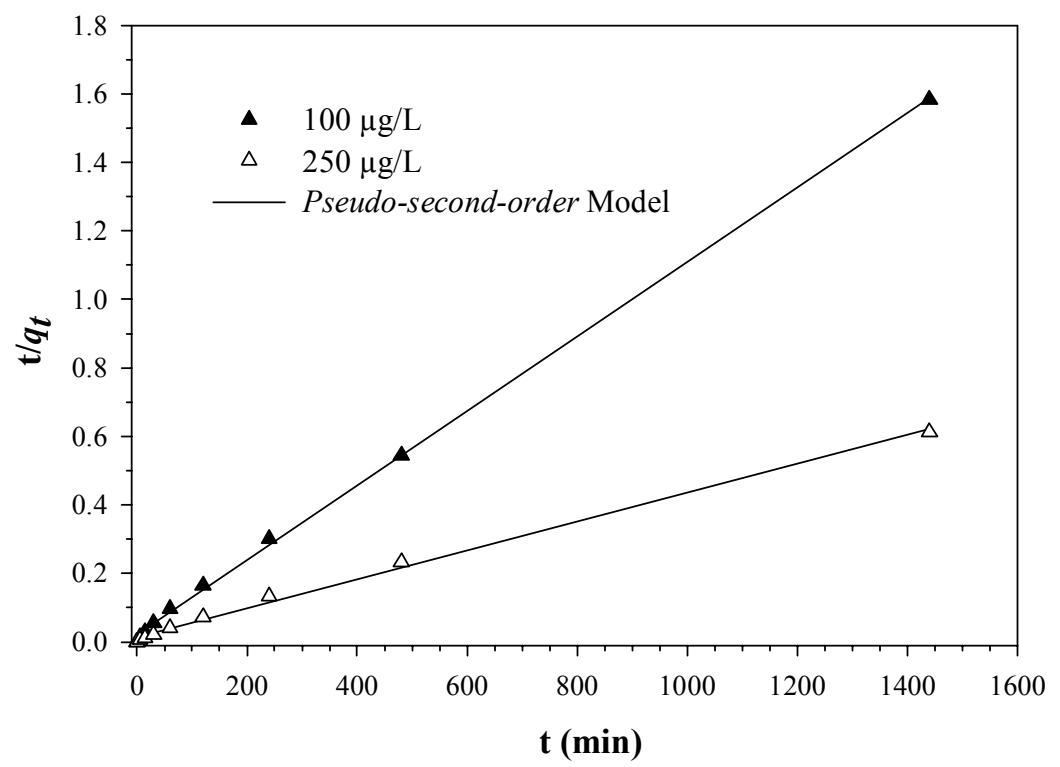

Figure 2.12 Pseudo-second-order kinetics for sorption of selenite by nano-magnetite (adsorbent dose $0.1 \mathrm{~g} / \mathrm{L}$; pH 4.0 \pm 0.1 ; mixing time $24 \mathrm{~h} ; 25^{\circ} \mathrm{C}$ ).

The experimental data fitted both the equations well. The values of $q_{e}$ calculated from both these models are compared with experimental values $q_{e}(\operatorname{Exp})$ (Table 2.3). The values of $q_{e}$ and $q_{e}$ (Exp) of the pseudo-first-order model differed greatly and the values of correlation coefficients are low thereby indicating the inapplicability of the model to the system. Whereas, the values of $q_{e}$ and $q_{e}$ (Exp) of the pseudo-second-order kinetic model were in excellent agreement exhibiting that the system obeyed the aforementioned model. 
The values of correlation coefficient were very high, hence affirming the applicability of pseudo-second-order model.

Table 2.3 Pseudo-first-order and Pseudo-second-order adsorption rate constants for the adsorption of selenite on nano-magnetite.

\begin{tabular}{cccccccccc}
\hline Concentration & \multicolumn{3}{c}{ Pseudo-first order kinetic } & \multicolumn{3}{c}{ Pseudo-second order kinetic } \\
\hline & $\begin{array}{c}\mathrm{K}_{1} \\
(\mu \mathrm{g}-\mathrm{Se} / \mathrm{L})\end{array}$ & $\begin{array}{c}q_{e}(\mathrm{Exp}) \\
(\mu \mathrm{g} / \mathrm{g})\end{array}$ & $\mathrm{r}^{2}$ & $\begin{array}{c}\mathrm{K}_{2}(\mu \mathrm{g} / \mathrm{g} \\
\left.\mathrm{min}^{-1}\right)\end{array}$ & $q_{e}(\mu \mathrm{g} / \mathrm{g})$ & $\begin{array}{c}q_{e} \text { (Exp) } \\
(\mu \mathrm{g} / \mathrm{g})\end{array}$ & $\mathrm{r}^{2}$ \\
\hline \multirow{2}{*}{100} & 0.006 & 447.0 & 909.6 & 0.9861 & 17107 & 909.0 & 909.6 & 0.9994 \\
250 & 0.003 & 1192.0 & 2350.3 & 0.9312 & 85625 & 2500.0 & 2350.3 & 0.9966 \\
\hline
\end{tabular}

\subsubsection{Interfering anions}

Presence of competing anions in the aqueous solution may interfere with Se adsorption onto the active sites of the nano-magnetite, and reduce the selenium removal efficiency. The results for percent selenium removal in the presence of competing anions such as chloride, sulfate and nitrate at initial selenite concentration of $250 \mu \mathrm{g}-\mathrm{Se} / \mathrm{L}$ at $\mathrm{pH}$ 4.0 are shown in Fig.2.13 (a). The presence of chloride and nitrate caused a minor reduction in selenite adsorption. Conversely, the presence of sulfate at $0.05 \mathrm{M}$ did not significantly affect the adsorption capacity of nano-magnetite, which indicated the adsorption of nano-magnetite for selenite was selective. A similar observation was made in case of a tropical soil as an adsorbent for selenite removal in which the presence of $\mathrm{SO}_{4}{ }^{2-}$ hardly affected selenite adsorption even when ionic strength was increased from 0.01 to $0.05 \mathrm{M}$ (Lim and Goh, 2004). Another study involving selenite removal using iron-coated granular activated carbon (GAC) also reported insignificant impact on selenite adsorption in the presence of $\mathrm{SO}_{4}{ }^{2-}$ ions (Zhang et al., 2008). The adsorption of 
selenite using manganese nodule leached residues was reported to have decreased from $91 \%$ to $74 \%$ and $80 \%$ in the presence of $\mathrm{SO}_{4}{ }^{2-}$ and $\mathrm{NO}_{3}^{-}$respectively (Dash., 2007). Since sulfate commonly occurs inevitably in mine influenced waters containing selenium, further investigation with different ionic strength of $0.01,0.03$ and $0.1 \mathrm{M}$ sulfate at initial concentration of $250 \mu \mathrm{g}$-Se/L and pH 4.0 was carried out (Fig.2.13 (b)). The presence of sulfate did not interfere with Se adsorption by nano-magnetite and actually enhanced selenium adsorption slightly. This finding illustrated nano-magnetite was promising in treating Se-containing mine water which is typically high in sulfates.

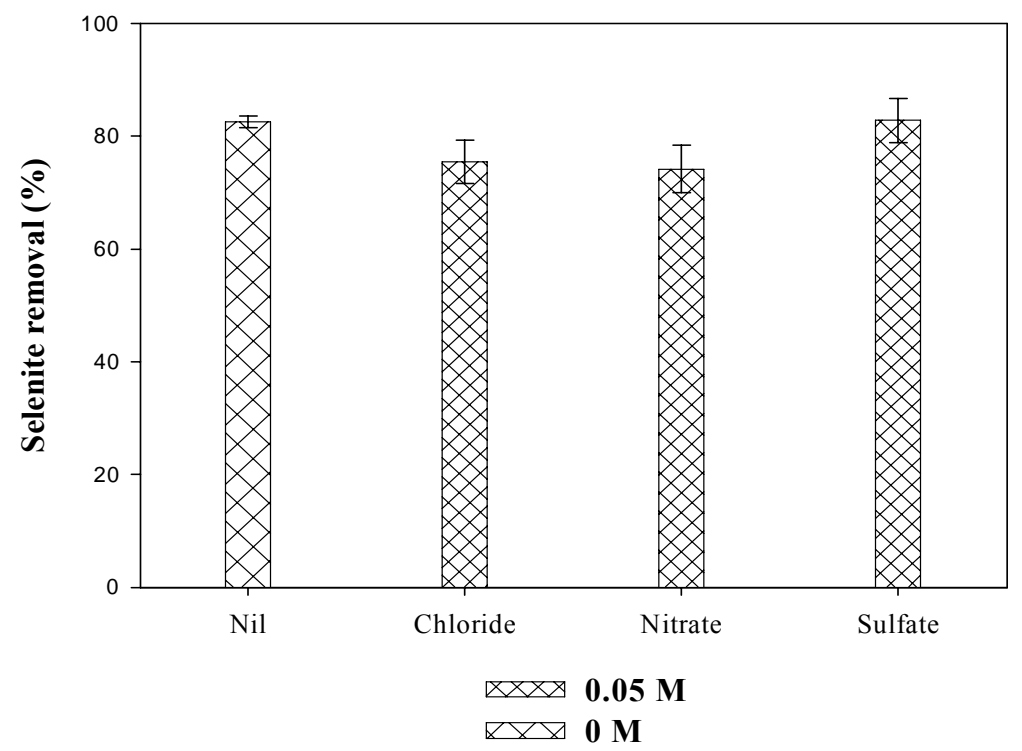

Figure 2.13 (a) Effect of anions on selenite removal by nano-magnetite (mixing time $24 \mathrm{~h} ; 20^{\circ} \mathrm{C}$; $\mathrm{pH} 4.0 \pm 0.1$; initial concentration $250 \mu \mathrm{g}-\mathrm{Se} / \mathrm{L}$ ). 


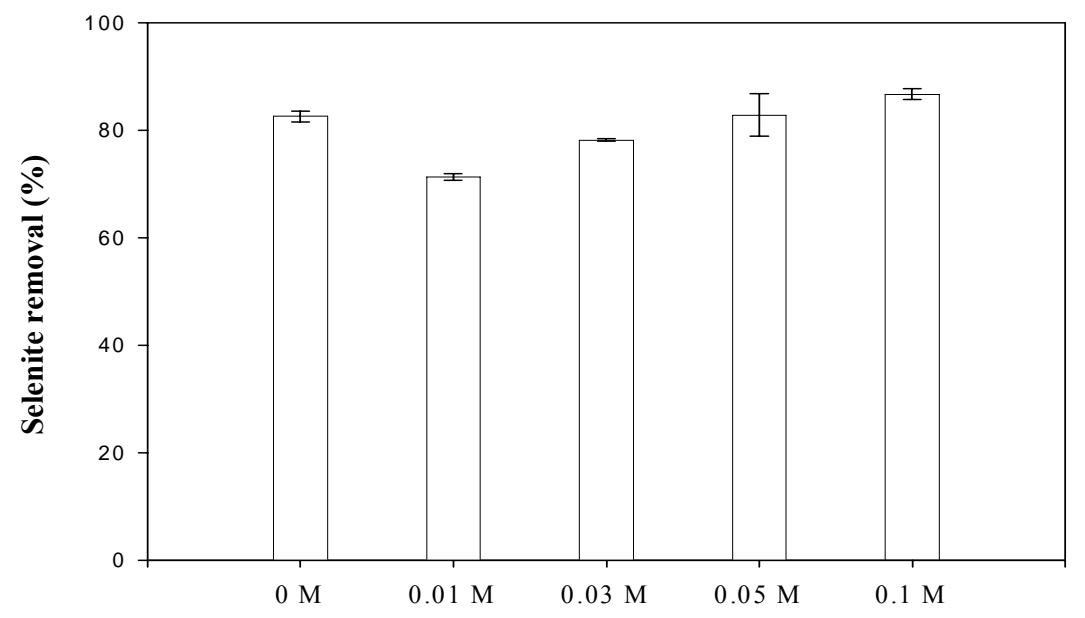

Figure 2.13 (b) - Effect of sulfate on selenite removal by nano-magnetite (mixing time $24 \mathrm{~h} ; 20^{\circ} \mathrm{C} ; \mathrm{pH} 4.0 \pm 0.1$; initial concentration $250 \mu \mathrm{g}-\mathrm{Se} / \mathrm{L}$ ). 


\subsection{Conclusions}

The use of nano-magnetite in the removal of selenite from water/wastewater was investigated in this study and the following conclusions can be drawn:

1. Nano-magnetite was found to be a better adsorbent for selenite when compared to either natural magnetite or nano-iron.

2. The results indicated that an effluent concentration of less than $5 \mu \mathrm{g}-\mathrm{Se} / \mathrm{L}$ could be achieved in removing selenite that occur at levels as low as $100 \mu \mathrm{g}$-Se/L comparable to those found commonly in mine influenced waters .

3. The high selenite removal efficiency in low $\mathrm{pH}$ range (i.e., 3.0-5.0) was an added advantage for nano-magnetite to be used in treating low $\mathrm{pH}$ water such as acidic mine water.

4. Adsorption of selenite onto nano-magnetite was a spontaneous, endothermic process and increasing temperature favors adsorption.

5. Isotherm studies showed that selenite adsorption onto the surfaces of nano-magnetite was heterogeneous with a maximum adsorption capacity of $\sim 10 \mathrm{mg}$-Se/g-adsorbent.

6. Presence of common anions did not significantly affect the adsorption capacity of nano-magnetite for selenite. The selective adsorption of nano-magnetite was greatly promising in removal of selenite from water with high sulfate, such as mine influenced water. 


\section{References}

Adams,D .J. and Pennington, P. (2005). "Selenium and arsenic removal from mining wastewaters.” 2005 SME Annual Meeting: Got Mining- Preprints, 385-388.

Balistrieri, S. L and Chao, T. T. (1990). "Adsorption of selenium by amorphous iron oxyhydroxide and manganese dioxide." Geochim Cosmochim Ac., 54(3), 739751.

Benjamin, M.M. (1983). "Adsorption and surface precipitation of metals on amorphous iron oxyhydroxide." Environ.Sci.Technol., 17(11), 686-692.

Chang, Y.C and Chen, D.H. (2005). "Preparation and adsorption properties of monodisperse chitosan-bound $\mathrm{Fe}_{3} \mathrm{O}_{4}$ magnetite nanoparticles for removal of Cu(II) ions." J. Colloid Interf. Sci., 283 (2005), 446-451.

Cornell, R.M., and Schwertan, U. (2003). "The iron oxides: Structure, properties, reactions, occurrences, and uses." Wiley-VCH GmbH\&Co. KGaA, Weinheim, Germany.

Cumbal, L.H. and Sengupta, A.K. (2005). "Preparation and characterization of magnetically active dual-zone sorbent." Ind. Eng. Chem. Res., 44(3), 600-605.

Dash, S.S and Parida, K.M (2007). "Studies on selenite adsorption using manganese nodule leached residues." J. Colloid Interf. Sci., 307, 333-339.

El-Shafey, E.I. (2007). "Removal of Se (IV) from aqueous solution using sulphuric acidtreated peanut shell." J. Environ.Manage., 84(2007) 620-627.

Eskandarpour, A., Sassa, K., Bando, Y., Ikuta, H., Iwai, K., Okido, M., and Asai, S. (2007). "Creation of Nanomagnetite aggregated iron oxide hydroxide for 
magnetically removal of fluoride and phosphate from wastewater." ISIJ Int., 47(4), 558-562.

Goh, K. H and Lim, T. T. (2004). "Geochemistry of inorganic arsenic ans selenium in a tropical soil: effect of reaction time, $\mathrm{pH}$, and competitive anions on arsenic and selenium adsorption.” Chemosphere. 55(2004), 849-859.

Hu, J., Lo, I.M.C. and Chen, G. (2004). "Removal of Cr(VI) by magnetite nanoparticle." Water Sci.Technol., 50(12) 139-146.

Kapoor, A., Tanjore, S. and Viraraghavan, T. (1995). "Removal of selenium from water and wastewater." Int. J. Environ. Stud., A \& B. 49(2), 137-147.

Lemly Dennis. A. (2004). "Aquatic selenium pollution is a global environmental safety issue." Ecotox. Enviro., Safe., 59(2004), 44-56.

Lenntech. (2008).Selenium, Lenntech Water treatment and Air purification Holding BV.

Linkson, P.B. (1990). "Stability of selenium in aqueous systems." Australian Chemical Engineering Conference (18 ${ }^{\text {th }}$ : 1990; Auckland, New Zealand), 161-168.

Mak, S.Y and Chen, D.H. (2004). "Fast adsorption of methylene blue on polyacrylic acid bound iron oxide magnetite nanoparticles.” Dyes Pigments. 61(1), 93-98.

Martinez, M. Gimenez, J., De Pablo, J., Rovira, M and Duro, L. (2006). "Sorption of selenium(IV) and selenium(VI) onto magnetite.” Appl. Surf. Sci., 252(10), 37673773.

Mavov, V., Stamenov, S., Todorova, E., Chmiel, H and Erwe, T. (2006). "New hybrid electrocoagulation membrane process for removing selenium from industrial wastewater.” Desalination. 201(2006), 290-296. 
Neuzil, S.G., Dulay, F. T., Cecil, C.B., Fedorko, N., Renton, J.J and Bhumbla, D.K. (2007). "Selenium concentrations in Middle Pennsylvanian coal bearing strata in the Central Appalachian basin." Open-File report. 2007-1090.

Oualid.H and Emmanuel. N.(2007). "Modeling of adsorption isotherms of phenol and chlorophenols onto granular activated carbon. Part I. Two-parameter models an equations allowing determination of thermodynamic parameters." J. Hazard. Mater., 147(2007), 381-394.

Parida, K.M., Gorai, B., Das, N.N and Rao, S.B (1997). “ Studies on ferric oxide hydroxides. III. Adsorption of selenite $\left(\mathrm{SeO}_{3}{ }^{2-}\right)$ on different forms of iron oxyhydroxides." J. Colloid Interf. Sci., 185(2), 355-362.

Renner, R. (2005). "Proposed selenium standard under attack." Environ. Sci. Technol., $39(6), 125 \mathrm{~A}-126 \mathrm{~A}$.

Rovira, M., Gimenez, J., Martinez,M., Martinez-Llado, X., Joan De Pablo, J., Marti, and Duro, L.(2008).“Sorption of selenium (IV) and selenium (VI) onto natural iron oxides: Goethite and hematite." J. Hazard. Mater., 150(2008), 279-284.

Shaik Basha and Bhavanath Jha. (2008). "Estimation of isotherm parameters of biosorption of $\mathrm{Cd}(\mathrm{II})$ and $\mathrm{Pb}(\mathrm{II})$ onto brown seaweed, Lobophora variegata." J.Chem.Eng. Data. 53, 449-455.

Sharmasarkar Shankar and Vance F. George. (2002). "Selenite-selenate sorption in surface coal mine environment." Adv. Environ. Res., 7, (2002), 87-95.

Suvardhan. K., Krishnaiah. L., Suresh Kumar. K., Rekha. D., Jayaraj.B., Ramanaiah.S and Chiranjeevi.P. (2005). "Studies of selenium in environmental samples and synthetic mixtures by spectrophotometry." Chemosphere. 62, 899-904. 
Tidwell, L., McCloskey, J., Joyce, H., Dahlgren, E and Hadden, A. (2005). "Removal of selenium oxyanions from mine water ulilizing elemental iron and galvanically coupled metals." Proceedings of the Jan D. Miller Symposium-Innovations in Natural Resource Processing, 299-313.

U.S.Department of Health and Human Services, (2001). "Draft toxicological profile for selenium.”

Wei, X. and Viadero. Jr., R.C. (2007). "Synthesis of magnetite nanoparticles with ferric iron recovered fron acid mine drainage: Implications for environmental engineering." Colloid Surface A: Physiochem. Eng. Aspects. 294(2007), 280-286.

WHO, (2003). "Selenium in drinking-water". Background document for preparation of WHO Guidelines for drinking-water quality. Geneva, World Health Organization. (WHO/SDE/WSH/03.04/13).

WV DEP, (2008). "West Virginia Integrated Water Quality Monitoring and Assessment Report." West Virginia Department of Environmental Protection, Charleston, WV.

WV Geological and Economic Survey, (Dec., 2005). "Trace Elements in West Virginia Coals." http://www.wvgs.wvnet.edu/www/datastat/te/index.html (accessed Dec., 2008)

Zhang, N., Lin, L.S. and Gang, D. (2008). “Adsorptive selenite removal from water using iron-coated GAC adsorbents.” Water Res., 42(2008), 3809-3816.

Zhang, P., and Sparks, D.L. (1990). "Kinetics of selenate and selenite adsorption/desorption at the goethite/water interface." Environ. Sci. Technol., 24(12), 1848-1856. 


\section{VITA}

Shilpa Bhojappa was born in The Nilgiris, Tamilnadu, India. She enrolled in Vishweswariah Technological University at Mysore in September 2001 and received her Bachelor Degree in Environmental Engineering in June 2005. She was admitted into West Virginia University in Spring 2007 and pursued her Master degree in Civil and Environmental Engineering. She worked under the supervision of Dr. Xinchao Wei and her work focused on removal of pollutants such as phosphorus and selenium from aqueous solutions using adsorption processes.

John

$\mathrm{H}$.

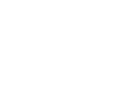

Hagen 